\title{
OBRAS MANUSCRITAS Y PAPELES DE CEÁN BERMÚDEZ EN LA BIBLIOTECA NACIONAL
}

Julián MARTIN ABAD

Hace algún tiempo, en mi diario de trabajo en la Sección de Manuscritos de la Biblioteca Nacional de Madrid, tuve la satisfacción de incorporar al Inventario general un conjunto de manuscritos en los que aparecía repetidamente, bien firmando, bien encabezando portadas, o como destinatario de diversos papeles, el nombre de Juan Agustín Ceán Bermúdez. Intenté conocer la fecha de ingreso de tal fondo en la Biblioteca y el posible vendedor o donante, pero mi búsqueda no dio resultado pasitivo.

En octubre de 1982 firmaba Francisco Aguilar Piñal la nota de agradecimiento que incluye en el Tomo II de su Bibliografía de Autores Españoles del Siglo XVIII, en el que dedica los números 2.646-2.697 a Ceán Bermúdez'. También ese mismo año venía a la luz una monografía de José Clisson Aldana, primer trabajo amplio sobre nuestro escritor y crítico de $\operatorname{arte}^{2}$. Esta coincidencia de fechas hace que resulte necesaria la consulta conjunta del repertorio y de la monografía para disponer de una bibliografía prácticamente completa. Sin embargo ninguno de los dos autores cita un trabajo previo de Juan Carrete Parrondo ${ }^{3}$, que también aportaba información de interés.

\footnotetext{
1 Madrid, C.S.l.C., Instituto •Miguel de Cervantes•, 1983. Se citará en lo sucesivo: Aguilar Piñal.

2 Juan Agustín Ceán-Bermúdez, escritor y critico de Bellas Artes. Oviedo, Instituto de Estudios Asturianos, 1982.414 p. Aguilar Pinal recogería la referencia en el Tomo III, aparecido en 1984, bajo el n. 4.856.

3 .Personajes de la bibliofilia española: Juan Agustín Ceán Bermúdez, historiador del arte del grabado y coleccionista de estampas, en Cuaternos de Bibliofilia, n. 3 (1980), p. 57-68. En el Boletín del Centro de Estudios del Siglo XVIII, n. 7 y 8 (1980), p. 264, ya se señaló el interés de este artículo.

No hay que olvidar que la obra de Clisson Aldana constituye su tesis doctoral leída en la Universidad de Oviedo ya en 1978.
} 
Realmente era muy reducido el número de los testimonios manuscritos de Ceán en la Biblioteca Nacional, pues sólo cabía añadir a los Mss. 2488, 2831 y 5622 , recordados por los autores anteriormente citados, el Mss. $12971^{25}$, un simple volante autógrafo ${ }^{4}$. El hecho de incorporar un número tal de mamuscritos en el que existen borradores y originales autógrafos, copias de obras ajenas publicadas e inéditas, junto con un número importante de papeles pertenecientes al célebre historiador del arte español, creo justifica sobradamente la presente noticia.

Publico un prólogo inédito de Ceán que ofrece los pormenores acerca de su trabajo con el manuscrito de las Noticias de los arquitectos y arquitectura de España de Llaguno y Amírola, noticias biográficas y bibliográficas propias y de Jovellanos, y noticias incluso sobre alguno de estos manuscritos que a continuación se in cluyen. Obra dicho prólogo en el Mss. $21458^{\text {ri }}$. Este mismo texto pone de manifiesto la forma de trabajar de Ceán y hace pensar sin duda en que algunos de los manuscritos que consideramos borradores autógratos lo son, no sólo por la presencia lógica de correcciones, sino por su mayor extensión respecto de los textos impresos o presentes en otros manuscritos que nos atreveríamos a calificar de originales autógrafos. Tal es el caso del Mss. $214.58^{\prime \prime}$ respecto a la Introducción del n. 4. del Mss. 21458 ', copia realizada por el segundo de sus hijos, Joaquín; y asimismo en el caso del Discurso preliminar incluido en ese mismo manuscrito respecto del texto impreso en 1829.

También nos hace pensar en la intervención directa de la mano de Ceán en ese conjunto de manuscritos en los que su autoría no puede desprenderse de los mismos, pero que presentan características típicas de su modo de laborar. Es el caso, por ejemplo, del Mss. 21457.

Agruparé las descripciones en siete apartados no rígidos, ordenadas en la medida de lo posible cronológicamente, precediendo las que poseen mención expresa de fecha.

a) Obras de Ceán Bermúdez:

1. Descripción de una Estampa de Juan de Herrera.

S. XVIII, 6 h., $205 \times 145 \mathrm{~mm}$, y 1 h., $210 \times 75 \mathrm{~mm}$.

Escrito dirigido a Antonio Ponz y fechado en Madrid, noviembre de 1779 . sobre una estampa de Otho van Veen. Se incluye la traducción, realizada por un amigo común, de los dísticos que acompañan a la imagen.

Mss. 2] 4.54

4 CI Mss. 3804, utilizado por Clisson Aldana, que es una colección de poesias de los siglos XVIJI y $\mathrm{X} 1 \mathrm{X}$, solamente incluye un soneto dedisado a Ceán y una oda a su esposa, pero ninguna obra de acjuél. 
2. Viages del Señor Cean por Andalucia, Estremadura, Murcia y Valencia. S. XVIII. 1 legajo, $210 \times 150 \mathrm{~mm}$.

Contiene: Viaje por Andalucía Extremadura y Murcia, realizado entre los días 24 de julio y 3 de noviembre, junto con Juan de Peña y un lacayo de éste $(7 \mathrm{f}$. dobl.); Viage á Valencia y Borrador sobre los Pintores de España, iniciado el 19 de mayo de 1788 (2 f. dobl.); Viage por Valencia en observacion de las tres bellas Artes ( $7 \mathrm{f}$. dobl.); y varias notas sobre pinturas y esculturas conservadas en Valencia (1l h. útiles).

Mss. $21454^{5}$

3. Discurso sobre el discernimiento de las pinturas, dibuxos y estampas originales de las copias.

S. XVIII. 26 h., $230 \times 190 \mathrm{~mm}$.

Fechado en Sevilla a 7 de Octubre de 1791.

Mss. $21458^{5}$

4. [Algunas fichas del "Diccionario histórico de los más ilustres profesores de las Bellas Artes en España y varias adiciones.]

S. XVIII. I legajo.

106 fichas de diversos tamaños y en ocasiones formando cuadernillos, correspondientes a otros tantos artistas. El texto en ocasiones coincide con la ed. del Diccionario (Madrid, Vda. de Ibarra, 1800.6 v.); a veces ofrece pequeñas variantes; existen además fichas de artistas no incluidos. Mss. $21455^{8}$

5. [Descripción artistica de la Catedral de Sevilla.] S. XIX. $145 \mathrm{f} .+7 \mathrm{~h}$. de guardas $(3+4), 210 \times 150 \mathrm{~mm}$.

Ene.: Hol., $222 \times 160 \mathrm{~mm}$.

De esta obra existe ed. de: Sevilla, Viuda de Hidalgo y Sobrino, 1804, XXII, 200 p. (de la que existe ejemplar en la Biblioteca Nacional, B.A. 20100, no citado por Aguilar Piñal, II, n. 2.673). El manuscrito no incluye la Tabla de los artistas...

V. Inventario General de Manuscritos de la Biblioteca Nacional, VIII; y Aguilar Piñal, II, n. 2.662.

Mss. 2488 (sign. antigua: H. 224)

6. Carta de D. Juan Agustin Cean Bermudez á su amigo Philoultramarino sobre El discernimiento de las pinturas originales y de las copias. S. XIX. 53 p., $210 \times 150 \mathrm{~mm}$.

En la portadilla: Sobre El conocimiento de las Pinturas originales y de las copias. En la p. 53 firma y la anotación: «Sevilla, 22 de agosto de 1805». 
Se ineluyó esta Carta en Minerva, 21-1-1806 y en El Arte en España, 2 (1863), p. 148-163. Existen buen número de variantes entre el texto manuscrito y el texto impreso.

Se conoce otro manuscrito, el 26.IV.27, del Instituto de Valencia de D. Juan, de Madrid (V. Aguilar Piñal, II, n. 2.660; y Gregrorio de Andrés: Catálogo de los manuscritos del Instituto aValencia de Don Juan. Madrid, 1983, n. 138). Mss. $214.54^{1}$

7. Carta de D. Juan Agustin Cean Bermudez á su amigo Philoultramarino, sobre El estilo y gusto en la pintura de la escuela sevillana. Y sobre El grado de perfeccion á que La elevó Bartolomé Estevan Murillo. Se inserta la vida de este celebre profesor, y se describen sus principales obras. 1805. S. XIX. 1 h. +179 p. +4 h. de guardas $(2+2), 180 \times 110 \mathrm{~mm}$. Enc.: Pasta española, $185 \times 115 \mathrm{~mm}$. Tejuelo: Pintur Sevilla.

Ed. en Cádiz, En la Casa de Misericordia, 1806; existe reimp. de Sevilla, Ayuntamiento. Delegación de Cultura. Sección de Publicaciones, 1968, 165 p. primeras (existe ejemplar en la Biblioteca Nacional, B.A. 12598). Algunas variantes. Mss. 21451

8. [Papeles varios sobre la aVida de Juan de Herrera».]

S. XIX. I legajo, $215 \times 155 \mathrm{~mm}$.

Contiene: una portada, con el texto: Vida de Juan de Herrera esforzado soldado de Carlos $V$, insigne arquitecto de Felipe $I I, y$ uno de los mejores matemáticos de su tiempo. Escrita por... Año 1812; Advertencia y copia del acta de la Junta de 5 de Junio de 1812 de la Real Academia de la Historia, en lo que se refiere a la censura de Martín Fernández de Navarrete y Juan C. Ramírez Alamanzón (junto con nota de posibles correcciones); Extracto de la vida de Juan de Herrera... y nota sobre el encargo de realizar el mismo para su lectura en Junta General de la Academia.

Mss. $214.54:$

9. [Nota necrologica del grabador Pedro González de Sepúlveda.] S. XIX (1815). 2 h., $210 \times 150 \mathrm{~mm}$.

Firma al fin. La muerte del grabador ocurrió en Madrid el 17 de mayo de 1815 .

Mss. $21455^{\prime}$

10. Ocios de D. Juan Agustín Ceán Bermúdez sobre Bellas Artes, escritos por el mismo en Madrid desde el año de 1816 al de 1822, que copia su hijo en el de 1833. Joaquin Cean-Bermudez: 1.-Advertencia. 2.-Manifestacion 
en la Academia de San Fernando de las obras pertenecientes á las Bellas -artes, executadas en este año de 1821 (p. 105-116). 3.-Escultura en España, su historia: a) Advertencia.-b) Primer Dialogo (p. 121-130).-c) Dialogo segundo (p. 131-143).-d) Dialogo tercero (p. 145-158). 4.-Catalogo raciocinado de las Estampas, que posee D. Juan Agustin Cean Bermudez, formado por el mismo. Y Ensayo para el de una Coleccion completa de Pinturas, Esculturas, Estampas, Diseños y otras obras de las Bellasartes. Principiado en Madrid el día 1. de Noviembre de 1819: a) Advertencia.-b) Introducion (p. 167-179),-c) [Introducciones a cada una de las escuelas] (p. 181-227).--d) Indice alfabetico de los Grabadores en dulce. contenidos en el Catalogo con la indicacion de los payses, ó escuelas á que pertenecen, y el numero de las Estampas de cada uno.

S. XIX. 23 h., $260 \times 195 \mathrm{~mm}$.

Al fin firma de Joaquín Ceán Bermúdez, en Madrid, a 15 de Agosto de 1839.

Según se desprende de la Advertencia primera la copia recogía las obras siguientes:

«De Arquitectura.

Discurso sobre el nombre, origen, forma, progresos y decadencia del Churriguerismo: folio.

Tres diálogos entre Juan de Herrera, arquitecto de Felipe II y Battista Antonelli, su ingeniero, sobre las grandes obras que executaron y lo mal premiados que por ellas fueron: folio.

Pintura.

Análisis del cuadro de Santa Justa y Santa Rufina que pintó D. Francisco Goya y Lucientes para la Catedral de Sevilla: folio.

Noticias exactas y curiosas del cuadro original de Rafael de Urbino, llamado el Pasmo de Sicilia que existe ahora en el real Museo de Madrid: folio.

...[y los tres conservados]".

Enrique Pardo Canalis en «Dos diálogos de Ceán Bermúdez sobre escultura en España», Revista de ideas estéticas, XX (1962), p. 351-377, edita parte de estos diálogos utilizando el manuscrito del Museo Lázaro Galdiano de Madrid, Mss. 120.

La introducción del n. 4 coincide exactamente con la publicada por Juan Carrete Parrondo en «Personajes de la bibliofilia española: Juan Agustín Ceán Bermúdez, historiador del arte del grabado y coleccionista de estampas», cit., p. 61-68, que utiliza el manuscrito de la Biblioteca Menéndez Pelayo, de Santander, M 245.

Mss. $21458^{\prime}$ 
11. El grabado (tachado: en dulce) de Estampas. Su invencion en Alemania y su propagacion en Europa en el siglo XV.

S. XIX. 10 pliegos dobl., $315 \times 215 \mathrm{~mm}$.

Se ha utilizado papel timbrado del año 1819. A pesar del título alcanza a los grabadores del siglo XVIII.

Mss. $21458^{+}$

12. [Obras varias]: 1.-Dialogo sobre el Arte de la Pintura, por Dn. Juan Cean. Madrid 31 de Octubre de 1818 (f. 1r-15r). 2.-Dialogo sobre el Arte de la Escultura. Madrid 12 de Diciembre de 1818 (f. 17r-78r): a) Primera Parte (f. 17r-34r).-b) ... Madrid 31 de enero de 1819. Segunda Parte (f. 37r-45r),-c) ...Madrid 12 de Febrero de 1819. Tercera Parte (1. 4.7r-59v).-d) ... 18 de Marzo de 1819. Quarta Parte (f. 61r-78r). 3.-Dialogo entre el Cardenal de España Dn Gaspar de Borja y Velasco ... y Dn. Juan Carreño de Miranda... Retratados en el tamaño del natural y en mediv Cuerpo: et primero por Dn. Diego Velazquez de Silva... y el segundo por at mismo Carreño. Son iguales, y se conserban en el estudio del aficionado à tas bellers artes Dn. Juan Agustin Cean Bermudez... (f. 79r-92r).

S. XIX. 92 f. +2 h. de guardas $(1+1), 205 \times 145$ mm. Lintre los I. 83 y 84 se incluye un f. pleg. (f. 83 bis y 83 ter) con una nota, suelto y de mayor tamaño: $200 \times 155$ mm.

Enc: Hol., $210 \times 150 \mathrm{~mm}$. Tejuelo: Dialogos de Cean. Ex-libris de Carlos José Ortiz de Taraneo.

El n. I editado en Sevilla, Manuel de Aragón y Cía, 1819. 58 p; existe reimp. de Sevilla, Ayuntamiento. Delegación de Cultura. Sección de Publicaciones, 1968, bajo el tít.: Carta de D. Juan Agustín Ceán Bermúdet a un amigo suyo, sobre el estilo y gusto en la piniura sevillana, 51 p. finales (V. n. 7). El ח. 3 en El Censor, n. 8, 23-XI-1820, 1. 2, p. 97-117, y en Ocios de D. Juan Agustín Cerin Bermúdez sobre Bellas Artes. Madrid, Amarita, 1822, p. 1-16, ed. no recogida por Aguilar Piñal, y de la que existe ejemplar en la Biblioteca Nacional, B.A. 2706. Mss, 21450

13. Dialogo sobre el arte de la Pinfurt. Madrid 31 de Octubre de 1818. S. XIX. $21 \mathrm{f} .+3$ h. de guardas $(1+2), 225 \times 165 \mathrm{~mm}$. Mss. $21455^{4}$

14. Historia del Arte de la Pintura...

S. XIX. 2 v, $215 \times 165 \mathrm{~mm}$.

Contiene: Tomo VI. Madrid 24 de Diciembre de 1824. 4h. $+347 \mathrm{p} .+8$ h.-Tomo VII. Madrid 30 de Mayo de 1825. 2 h. +323 p. +9 h. 
Se trata de una copia del manuscrito de la Real Academia de Bellas Artes de San Fernando, pues en los índices que se añaden al final de ambos tomos se indican Páginas del tomo de la Academia e Id. del presente. Sobre dicho manuscrito puede consultarse Enrique Lafuente Ferrari: "Una obra inédita de Ceán Bermúdez: La Historia del Arte de la Pintura , en Academia: Anales y Boletín de la Real Academia de Bellas Artes de San Fernando, III época, I (1951-52), p. 149-243 y II (1953), p. 25-72.

Mss. $21456^{1-2}$

15. 1.--Armada de Magallanes al Maluco (f. 1-15). 2.-Noticias de las armadas que fueron al Maluco en el reynado de Carlos $V$ (f. 17-54).

S. XIX. 54 f., $220 \times 150 \mathrm{~mm}$. (varios tamaños).

El n. 1 es una copia y el 2 un original autógrafo con tachaduras, correcciones y notas marginales.

V. Inventario General de Manuscritos de la Biblioteca Nacional, X; y Aguilar Piñal, II, n. 2.622.

Mss. 5622

16. [Discurso ante la Real Academia de Bellas Artes de San Fernando presentando su Discurso preliminar a las Noticias de los Arquitectos y Arquitectura de España. de Eugenio Llaguno y Amírola.]

S. XIX. 4 h. útiles, $215 \times 150 \mathrm{~mm}$.

Mss, $21456^{7}$

17. Breve Resumen de las Noticias de los Arquitectos y Arquitectura de España. Escritas por el señor D. Eugenio Llaguno y Amirola. Mlustradas y acrecentadas por D. Juan Agustin Cean-Bermudez. Madrid, á VIII de Noviembre. Año de M.DCCC.XV.

S. XIX. 4 h. +197 p. +52 h. +4 h. de guardas $(2+2), 230 \times 205 \mathrm{~mm}$. Sign.: $A^{4} B-Q^{6} R^{4} S-Z^{6} A A-C C^{6}$

Enc.: Hol., $240 \times 205 \mathrm{~mm}$. Tejuelo: Resumen

Contiene el resumen de los 5 tomos; un Catalogo Alfabetico de los Arquitectos, contenidos en el Resumen; y un Catálogo alfabético de los Pueblos, donde se construyeron los Edificios, contenidos en el Resumen.

Dice en la advertencia: «Entre los grandes bienes que goza el hombre, no es el menor poder disfrutar del tiempo a su placer. Bienaventurado el que le emplee en provecho del prójimo; y maldito sea el haragán, que se alimenta con el sudor y a costa de los demás. No por esto se debe creer exceptuado de esta maldición quien, aparentando graves, e importantes negocios, pase encerrado en una pieza por obligación algunas horas del día, y ocupe tan precioso tiempo en rutinerías, y 
en conversaciones, que aun en el caso de no ser más que inútiles, serán siempre perjudiciales, sin hacer ningún bien al virtuoso ciudadano, que le mantiene, ya sea porque no sabe hacerle, 9 ya porque su torcida intención no le incline a ello. Pero bienaventurado el otro, que no pensando más que en la felicidad de su patria, y sin la responsabilidad de éste, estudia, medita y trabaja de día y de noche a sus solas por conseguirla.

Ya se dijo en el prólogo de esta obra, que dueño el Editor de todo el espacio que hay desde que el sol asoma por el oriente hasta que se precipita en occidente, procuraba emplearle en obsequio e ilustración del público, trabajando incesantemente en aumentar y perfeccionar las vidas de nuestros arquitcctos. Concluidos, si pueden estarlo, los cinco tomos de que se compone la obra, trazó un breve Resumen, o compendio de toda ella, sin perjuicio de añadir en sus respectivos lugares las noticias que en adelante descubriese.

Cuatro motivos le obligaron a ello. 1. tener a la mano un prontuario cronológico de todos los profesores que comprende, y con él evitar repeticiones de unos mismos sujetos en unos mismos años; 2. poder colocar sin trabajo y sin equivocación las nuevas adquisiciones en sus correspondientes sitios; 3. hallar con facilidad y a renglón seguido los edificios que cada autor levantó; y $4 .^{\circ}$ que la suma atención, que se necesita para ejecutar el nuevo plan, por ser prolijo y embarazoso, distraiga al Editor de las amarguras que le rodean, y lo obligue a pensar solamente en lo que trabajare. Recurso prudente y necesario para poder conseguir alguna tranquilidad; y engaño que todo hombre sensible, aplicado y pundonoroso debe hacerse a sí mismo, cuando no está en su alcance otro remedió (sign. A2).

-Las ventajas del Resumen y Catálogos, cuyo trabajo algunos tendrán por ímprobo, serán conocidas y estimadas cuando el lector apresurado halle en un momento con estos socorros cuanto desee averiguas de lo que se contiene en las Noticias de los arquitectos y arquitectura de España. Entonces, así como el caminante en una noche obscura se alegra al encontrar un pontón sobre un peligroso arroyo, bendicirá el tiempo que se empleó en trazarlos, el buen deseo y la benéfica intención de quien con tanta uti lidad le supo aprovechar en su ejecución a costa de repetidas equivocaciones; y confesará que no deben publicarse obras de esta clase sin tales auxilios* (sign. A4). Mss. 21453

18. [Varios vocabularios de arquitectura:] 1.-Copia de voces antiguas, derivadas del arabe, pertenecientes a la arquitectura, y de las que todavia se usan algunas en las provincias de España (8 h.). 2.-Copia de Voces tecnicas de Arquitectura que tienen origen arabe, y uso en varias provincias de España (4 h.). 3.- OOtro vocabulario recogiendo los términos traducidos del árabe más libremente] (2 h.)

S. XIX. 14 h., varios tamaños.

Ms5. $21456^{3}$ 
19. [*Prólogo para cuando se imprima esta obra y "Discurso preliminar $a$ las] *Noticias de los Arquitectos y Arquitectura de España desde su restauración. Por el Señor D. Eugenio Llaguno y Amirola. Ilustradas y acrecentadas con notas, Adiciones y Documentos Por D. Juan Agustin Cean-Bermudez.

S. XIX. 64 h., $245 \times 185 \mathrm{~mm}$.

No se trata, como se ve, de la obra completa. Aparte de una portada, incluye el Prologo y el Discurso preliminar, éste con correcciones y tachaduras, que hacen pensar en un borrador, con texto más extenso que el incluido en la ed. de: Madrid, Imprenta Real, 1829, de la que existe ejemplar en la Biblioteca Nacional B.A. 1520-3, no recogido por Aguilar Piñal, II, n. 2.683.

Mss. $21458^{6}$

20. Versos míos: 1.-A un devoto impertinente, que rezaba á voces en la iglesia

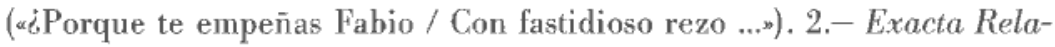
cion de un Baile y Cena celebrados en Madrid la noche del 23 de Enero de este año de 1790. Compuesta por un Abate Ynglés, y traducida al verso castellano por un Comico de la nueva Compañia del Teatro Asturiano de la Calle Ancha de San Bernardo ( EErase que se era, / vá de cuento Anton ...»). 3.-[Poema] ( $(\mathrm{Ni}$ el peligroso viage / que el valiente Perseo...*). 4.-Cantinela ( $\alpha$ Tocame tu Nicenta / el sonoro instrumento ...*). 5.-Monostrophe al Otoño ( $(\mathrm{D} \text { espues que los calores / con el Estio espiran, ... })^{\circ}$. 6.-Endecha («Amor engañoso, / que con dulce flecha, ...*). 7.-Endecha (*Mi dulce Theresa, / Mis tiernas delicias...*). 8.-Al Amór («No tienes que cansarte, / ven dado Diosecillo, ...

S. XVIII:XIX. 1 legajo, varios tamaños.

En el poema n. 8 una estrofa repetida dice: «Que Fasquina es de Felix / y Felix es mi amigo, / y à la amistád sincera / no ofendera Ceanino». Mss. $21455^{3}$

b) Materiales utilizados e instrumentos creados para la composición de sus obras:

21. Verdad desnuda. Y descripcion de la Portada, y de la Escalera Principal, en el Real Seminario de San Telmo, con las doctrinas, y Reglas de los Maestros y Escriptores mas clasicos y experimentados en suntuosos y magnificos Edificios de Arquitectura que an dirigido y Practicado en la Europa...

S. XVIII. 54 f., $215 \times 155 \mathrm{~mm}$.

Al fin: $\propto Y$ este es nuestro parecer como tales Artifizes Arquitectos, y lo fir- 
mamos en veinte y cinco días del mes de Marzo de 1726. Dn. Diego Antonio Diaz. Dn. Bartholome Martin. Dn. Francisco Martínez.*

Mss. $21455^{\prime \prime}$

22. [Papeles varios sobre la amenaza de ruina de la Capilla o Parroquia del Sagrario de la Catedral de Sevilla entre los años 1776 y 1777 :] 1.-Dudas, o reparos, que se le ofrece à un ignorante sobre el papel mano escripto, que hà salido de la remodemasion del Sagrario (3 f. dobl.). 2.-Respuesta de don Gazofilacio à don Zintorafilacio. [10 de Agosto de 77/ (9 f. dobl.). 3.CCopia sin firmas del Informe de los Maesfros Arquitectos de la Giudad de Sevilla sobre el estado del Templo del Sagrario y posibilidades de reparación. 29 de Diciembre de 1777) (3 f. fobl.)

S. XVIII. I legajo, varios tamaños.

Mss. $21458^{15}$

23. Plezts famosas de Pintura, Escultura y Arquitectura que hai en la Ciudad de Sevilla, en Sitios Publicos, y algunas Cosers particulares con los nombres de sus Autores.

S. XVIII, $40 \mathrm{t}, 210 \times 150 \mathrm{~mm}$.

Mss. $21454^{*}$

24. Reflexiones hechas sobre una pintura original (cuio autor se ignora), que para en poder de un aficionado de [Sevilla], (tachado: hechas) con el motive de haverla despreciado un (tachado: Director de esta Escuela de las tres bellas Artes; y superpuesto:) Profesor de este (tachado: Arte) facultad, teni (tachado: da) endola por copit, mal divu fjal da, mal pintada, y otros defectos: escriviotas en esta misma Ciudad otro aficionado, en honor del Arte y de la Verdad. Atio de 1778.

S. XVIII. 22 f., $210 \times 155 \mathrm{~mm}$.

Numerosas tachaduras y correcciones.

Mss. $214.54 .^{8}$

25. Reparos sobre la tradicion que asegura que Coello tardó en pintar el Quadro de la colocacion de la Santa Forma, que está en la Sacristía del Escorial siete ó (tachado: nuebe; y superpuesto:) 14 años.

S. XVIII:XIX. 21 h., $200 \times 145 \mathrm{~mm}$.

Una primera parte lleva el título: Descripcion de la pinfura de la Santa Forma; falta la segunda parte anunciada bajo el título de Composicion.

Mss. $21454^{6}$ 
26. Estatutos para el gobierno de la real Escuela del Diseño de Sevilla, y para el Estudio de las tres bellas Artes en ella. 1807.

Mss. $21454^{10}$

S. XIX. 4 h. +30 p., $210 \times 155 \mathrm{~mm}$.

27. [Carta.]

S. XIX. 4 h., $210 \times 150 \mathrm{~mm}$.

Parece tratarse de la respuesta de un amigo o aficionado a las Bellas Artes en relación con la edición de las Noticias de los arquitectos y arquitectura de España...

Al fin, de distinta mano y a la que se deben algunos añadidos en el texto, se dice: «Se dictó en la cama, y va de mano agena porque la cabeza anda debil, y algo dolorida. Así salio ello. Las ideas se han repetido mas veces, mas ahora van algo mas ordenadas á Dios. (Rúbrica). 4 Febrero 1809».

Mss. $21455^{2}$

28. Arboles historicos de las vidas de los Pintores Españoles.

S. XIX. I legajo, varios tamaños.

Comprende: Castilla, Andalucía, Valencia y Zaragoza.

Mss. $21458^{2}$

29. Catálogo de los profesores mas distinguidos de las bellas artes en España, acreedores a que seles graben inscripciones en los templos.

S. XIX. 32 p. +2 h., $300 \times 210 \mathrm{~mm}$.

Se presenta el Catálogo en cinco columnas encabezadas: Nombre; Profesiones; Años; Templos; Pueblos. En el encabezamiento del catálogo se indica: «La estrellita de la tercera columna indica los años en que florecieron; y quando no la tiene, el año en que murieran. En la quarta columna se señalan los templos en que se deben colocar las inscripciones, ya sea por que fueron sepultados en ellos, lo que se distingue con la letra $\mathrm{A}$ : ya por ser iglesias matrices, con la B; y ya por conservarse en ellos sus mejores obras, con la C.w

Se incluyen dos apartados al final: Islas y América; y un Suplemento. Finalmente una Lista de los Pueblos contenidos en este Catalogo. Mss. $21458^{12}$

30. Ensayo para el arreglo por Escuelas ò Reynos de una Coleccion de Estampas escogidas, con los nombres y marcas de sus gravadores, los de los pintores à esculptores de quienes copiaron; sus asuntos; el modo con que estan gravadas y sus años. $Y$ un Indice alfabetico de los nombres de todos los 
gravadores, pintores à esculptores, con el número de estampas que cada uno tiene en este arreglo, refiriendose a los folios en donde se hallan. S. XIX. 1 h. +24 p. +4 h., $345 \times 220 \mathrm{~mm}$.

Enc.: Hol., $350 \times 225 \mathrm{~mm}$.

Mss. 214.57

31. Noticia de los Arquitectos Arabes de que la hallamos por las inscripciones. S. XIX. 1 h., $295 \times 210 \mathrm{~mm}$.

Al pie de la Noticia nota dirigida a Juan Agustín Ceán Bermúdez, firmada por Cornide, que envía dichas Noticias y pide información bibliográfica, haciendo mención expresa de la Librería del Conde del Aguila. Para las relaciones de Ceán con José Andrés Cornide de Felgueira y Saavedra, véase Clisson Aldana, Op. cit., p. 336 .

Mss, $21458^{\text {? }}$

c) Obras ajenas anotadas, traducidas, cxtractadas o utilizadas:

32. LAnotaciones manuscritas en un ejemplar de la obra siguiente: Estatutos de la Real Academia de S. Fernando. En Madrid, Fn Ciasa de D. Gabriel Ramírez, 1757. 102 p., 1 h.; 8. $\left.{ }^{\circ}\right]$

Las anotaciones autógrafas de Ceán Bermúdez en las p. 9-17, 22, 26-31, $33-34,37,39,45-46,50-51,53-55,59,63,65,69-70,72-74,78-82,84-85$ у 87. Mss. 21452

33. Arte de Pintura de Mr. Carlos Alfondo du Fresnoy, traducido del verso latino à la Prosa Española por D.J.A.C.B. año de 1779.

S. XVIII. I legajo, $205 \times 150 \mathrm{~mm}$.

Contiene un borrador de la traducción y una copia caligráfica; y Notas al Arte de Pintura de Mr. Carlos du Fresnoy.

Tal vez utilizó la siguiente edición: Caroli Alphonsi Du Fresnoy et Francisci Mariae Marsy de pictura carmina elegantissima, iterum edidit Chist. Adolphus Klotzins. Lipsiae, Sumptibus Societatis librariorum, 1770. 64 p.; 8.. Mss. $21454^{7}$

34. [JOVELLANOS, Gaspar Melchor de: Carta de su amigo Philoultramarino fechada en 1 de Mayo de 1805 sobre la arquitectura inglesa.]

S. XIX. $13+3$ f. pleg., $210 \times 150 \mathrm{~mm}$.

El texto en B.A.E., 87, p. 365-382.

Mss. $21456^{4}$ 
35. [HOLANDA, Francisco de:] De la Pintura antigua. Libro segundo.

S. XVIII. $67 \mathrm{f}$. pleg, $205 \times 150 \mathrm{~mm}$.

En la cubierta de papel: «copia de Decbuxo (?) en el Año de 1798.

Es copia del manuscrito existente en la Real Academia de Bellas Artes de San Fernaudo, correspondiendo el texto a las p. 141-223 de: De la pintura antigua por Francisco de Holanda (1548); versión castellana de Manuel Denis (1563). Madrid, Academia de Bellas Artes de San Fernando y a expensas de su Director el Excmo. Sr. Conde de Romanones, 1921.

Mss. $21455^{7}$

36. Extracto de un precioso libro manuscrito original, que se conserva en la Biblioteca de la real Academia de San Fernando, à la qual le dexó por su muerte el erudito D. Felipe de Castro, Director de Escultura en la misma Academia, primer Escultor de Fernando VI, é individuo de la Roma con el nombre de Galesio Libadico [: Francisco de Holanda sobre la pintura antigua y sobre El sacar al natural]

S. XVIII. 1 h. +58 p., $210 \times 155 \mathrm{~mm}$.

El manuscrito de la Biblioteca de la Real Academia de Bellas Artes de San Fernando fue editado por Elías Tormo, según se ha indicado en el n. 35. Mss. $21455^{5}$

37. QUILLET, Frederic: Catálogo de la coleccion de cuadros que poseía el Príncipe de la Paz en 1808, formado por Mr. ...(Archivo general Central= Estado, leg. ${ }^{\circ}$ 1075).

S. XIX, $22 \mathrm{~h}$. útiles, $330 \times 225 \mathrm{~mm}$.

Dedicado al Príncipe de la Paz, da noticia de 972 cuadros con indicaciones sobre su calidad artística. Texto en francés.

Mss. $21458^{3}$

d) Correspondencia:

38. [Cartas de Don Martín Fernández de Navarrete, Don Juan Agustín Ceán Bermúdez, Don Diego Clemencín y Fr. Cirilo Alameda, a Don Tomás González, sobre investigaciones literarias, artísticas e históricas. Madrid, 1815-1820.]

S. XIX. 183 f. +2 h. de guardas $(2+2), 210 \times 150 \mathrm{~mm}$.

Enc.: Hol., $225 \times 160 \mathrm{~mm}$.

Las cartas de Ceán Bermúdez, que ocupan los f. 101 a 125, han sido editadas por Manuel Serrano Sanz y Francisco Javier Sánchez Cantón: V. Inventario General de Manuscritos de la Biblioteca Nacional, IX.

M8s. 2831 
39. Sobre la entrega de los dos baules de papeles del Sr. Jove Llanos. S. XIX. I legajo, varios tamaños.

Cuatro cartas originales de Baltasar de Cienfuegos Jovellanos dirigidas a Céan Bermúdez exigiendo la entrega de *dos baules con legajos manuscritos* de Gaspar Melchor de Jovellanos, fechadas en Madrid a $31-X-1813,3$ y 4-XI-1813 y 23-XII-1813. Copias de las respuestas dadas por Ceán Bermúdez a cada una de ellas con fechas $31-\mathrm{X}-1813,3$ y 5-XI-1813, y recibí firmado por el sobrino y heredero de Jovellanos a $28-\mathrm{XII}-1813$.

Carta del mismo Baltasar de Cienfuegos, de fecha 1-III-1814, exigiendo alguno de los trabajos no incluidos en dichos baules y reclamando determinados derechos respecto a las Memorias para la vida del Exano. Sr. D. Gaspar Melahor de Jovellanos ... (Madrid, 1814).

Contiene además copia de un escrito de Ceán Bermúder fechado en Madrid a 6-III-1814, dirigido al citado Baltasar de Cienfuegos, con el que remitía una cuenta presentada por D. Pedro del Río sobre determinados gastos de locomoción de Jovellanos, en 1808 , no abonados a dicho señor; citación para un juicio conciliatorio con el citado sobrino de Jovellanos y en relación con las Memorias...; finalmente documento firmado por Joaquina Serrada, en Madrid a 29-1V-1814, justificativo de la entrega a la misma, por parte de Ceán Bermúdez, de varias pinturas. Mss. $21988^{\prime}$

e) Archivo particular:

40. [Certificación de la Real Arademia de Bellas Artes de Sevilla sobre la pertenencia a la Escuela, y el buen aprovechamiento de las enseñanzas, de Juan Agustin Ceán Bermúdez. 4 de Agosto de 1776.]

S. XVIII. 2 h. útiles, $300 \times 210 \mathrm{~mm}$.

Mss. $214.58^{1 \text { H }}$

41. [Certificación del Secretario perpetuo de Ln. Real Academia de la Historia. del acta de la Junta ordinaria de 3 de noviembre de 1815 concediendo lirencia a Juan Agustín Cean Bermúdez para la utilizacion de libros prohibidos, de acuerdo con las condiciones estublecidas en Decreto, que se inserta, del Inquisidor Gesneral, Felipe Bertrán, de fecha 14 de febrero de 1783. 10 de Noviembre de 1815.]

S. XIX. 2 h. útiles, $290 \times 210 \mathrm{~mm}$.

Mss. $21458^{10}$

42. [Carta de Isidoro Bosarte, en nombre de la Real Academia de Bellas Artes de San Fernando, a Juan Agustís Ceán. Bermúdez, participándole el nombramiento de Académico de honor en la Junta de 1 de julio de 1798, a 
propuesta de Bernardo Iriarte; y borrador de la respuesta de Ceán, de fecha 3 de julio del mismo año.]

S. XVIII. $2+2$ h. útiles, $210 \times 150 \mathrm{~mm}$.

Mss. $21456^{8}$

43. Plan de Estudios para la Academia de San Fernándo propuesto por profesores en 1799, con obgeciones del Señor Cean.

S. XVIII. I legajo, $210 \times 150 \mathrm{~mm}$.

Contiene: Escrito de fecha 20 de mayo de 1799, firmado por Isidoro Bosarte, remitiendo a Ceán el Plan para su reconocimiento, y al margen, escrito de éste devolviendolo junto con el informe, fechado en Madrid a 24 de mayo de 1799; Plan nuevo de Estudios propuesto por 14 profesores à la Academia de San Fernando, para estudiar las bellas Artes en ella; Libros ó quadernos que la Academia de San Fernando deberá formar, imprimir y gravar, si adopta el plan de estudios propuesto por los profesores en 5 de Mayo de 1799; y las objecciones o puntualizaciones.

Mss. 21454

44. [Carta de la Real Academia de San Luis de Zaragoza a Juan Agustín Ceán Bermúdez, participándole el nombramiento de Académico de Honor; y escrito de éste agradeciendo el citado nombramiento, de fechas 20 y 24 de Diciembre de 1800 , respectivamente.]

S. XVIII. 4 h. útiles, varios tamaños.

Mss. 21458

45. [Carta de Juan Agustín Ceán Bermúdez a Isidoro Bosarte, dándole cuenta de su marcha a Sevilla y poniendose a disposición de la Real Academia de Bellas Artes de San Fernando de dicha Ciudad. Madrid, 6 de junio de 1801.]

S. XIX. 2 h. útiles, $205 \times 150 \mathrm{~mm}$.

Se añade la nota: «Acompaño las noticias que el Academico D. Marcos de Orellana me dirigio para el Diccionario de los Artistas, à fin de que existan en la Biblioteca de la (tachado: mi) Academia», pero no se conservan unidas dichas noticias.

Mss. $21456^{11}$

46. [Carta circular impresa de Joaquín Juan de Flores, en nombre de la Real Academia de la Historia, remitiendo *un ejemplar de la Real Cédula de 6 de julio próximo, en que se aprueba y manda observar la instrucción que formó en cumplimiento de real órden sobre el modo de recoger y conservar 
los munimentos antiguos descubiertos, ó que se descubran en el reyno ...* y dirigida a Juan Agustin Ceán Bermúdez con fecha 16 de Agosto de 1803; y acuse de recibo al margen, fechado a 25 de los mismos mes y año.] \$. XIX. 2 h. útiles, $215 \times 150 \mathrm{~mm}$.

Mss. $214.56^{9}$

47. [Cara de Cayetano de Urbina, como Presidente de la Real Academia de. San Carlos de Valencia, a Juan Agustín Ceán Bermúdez, participándole el nombramiento de Académico de Honor. Valencia, 4 de Agosto de 1804.] S. XIX. 2 h. útiles, $305 \times 215 \mathrm{~mm}$.

Mss. $21458^{14}$

48. [Informe de José de Vargas y Ponce, Pedro Arnal y José Isidro Morales, fechado en Madrid a 2 de Febrero de 1805 sobre la conveniencia de domiciliar en Sevilla un profesor que diera origen a una Escuela de Grabado. Se toma como justificactón la necesidad de publicar un volumen de ilustraciones que sirviera de complemento a la -Descripción artística de la Catedral de Sevilla* de Juan Agustín Ceán Bermúdez.

S. XIX. 2 pliegos dobl., $295 \times 210 \mathrm{~mm}$.

Se trata de una copia autentificada por Isidoro Bosarte.

Mss. 21458"1

49. [Original y copia de una cata dirigida a Juan Agustín Ceán Bermúdez por Joaruín Juan de Flores, en nombre de la Real Academia de la Historia, agradeciendo el envio de ejemplares de su «Descripción artística de lo Catedral de Sevilla y de su Descripción artística del Hospital de la Sangre de Sevilla. Madrid, 5 de Febrero de 1805.]

Mss. $214.58^{9}$

S. XIX. 2 pliegos dob., $295 \times 215$ y $310 \times 215 \mathrm{~mm}$.

50. [Carta de Joaquin José de Flores, en nombre de la Real Academia Española, a Juan Agustín Ceán Bermúdez, agradecienda su actuación ken el traslado y remesa de los papeles originales que descubrió en el Archivo de Yndias de Sevilla, pertenecientes á la vida de Miguel de Cervantes Saavedra.. Madrid, 4 de Junio de 1808.]

S. XIX. 2 h. útiles, $210 \times 150 \mathrm{~mm}$.

Mss. $2 \mathrm{~J} 456^{5}$

51. CCarta de Pedro Franco, Vice-protector de la Real Academia de Bellas Artes de San Fernando, a Juan Agustín Ceán Bermudez, participándole el 
nombramiento de Consiliario; y carta de éste agradeciendo el honor, fechadas en 3 y 4 de febrero de 1824, respectivamente.]

$\mathrm{S}$. XIX. $3 \mathrm{~h}$. útiles, varios tamaños.

Mss, $21456^{13}$

52. [Informe favorable al nombramiento como Académico supernumerario de la Real Academia de la Historia de Juan Pablo Pérez-Caballero, autor de un discurso titulado sIntroducción y progresos del Derecho romano en España. Su falta de autoridad y daños que ha acarreado su observancia. Madrid, 1 de abril de 1824.]

S. XIX. 2 h., $210 \times 150 \mathrm{~mm}$.

El informe lleva la firma de Ceán.

Mss. $21456^{6}$

53. [Correspondencia entre el Duque de Hijar, Marqués de Orani, Director del Museo del Prado, y Juan Agustín Ceán Bermúdez:] 1.-[Nota sobre dicha correspondencia] (2 h.). 2.-[Carta a Ceán solicitándole indique los pintores, escultores y arquitectos españoles cuyos bustos deben figurar en los 16 medallones de las principales fachadas del Museo del Prado y respuesta. de éste adjuntando nota] (3 h.). 3.-INueva carta a Ceán y respuesta de éste, adjuntando nota, sobre el mismo asuntol (3 h.).

S. XIX. (1828). I legajo, varios tamaños.

Mss. $21458^{10}$

54. [Certificación de Diego Clemencín, Secretario perpetuo de la Academia de la Historia, sobre la lectura del papel de Juan Agustín Ceán Bermúdez «Origen del Churriguerismo. en la sesión de 15 de noviembre de 1816, expedida a petición del mismo y fechada a 24 de diciembre de 1816.] S. XIX. 1 pliego dobl., $305 \times 210 \mathrm{~mm}$.

Ms8. $21458^{13}$

f) Papeles de carácter administrativo:

55. [Volante autógrafo como Jefe de División del Ministerio de Negocios Eclesiásticos. Madrid, 25 de Octubre de 1811.]

S. XIX. 1 h., $165 \times 110 \mathrm{~mm}$.

Mss. $12971^{25}$

56. Academia de la Historia. De la Tesoreria, hasta que falleció el Sor. D. Juan Agustin Cean-Bermudez en 3 de Diciembre de 1829 y despues hasta 4. de Enero de 1830 en que su hijo entrego el liquido que resultó á favor de 
la misma Academia: 1--Documentos para poder cobrar por los Academicos ausentes [: autorizaciones firmadas por Diego Clemencín; Francisco Martínez Marina; Julián Pablo Conde, como heredero de José Antonio Conde; Teresa Rui-Bamba, como heredera de Ambroxio Rui-Bamba, folas del año 182t]. 2. - Yota de las obras de la Real Academian de la Historia entregadas para ol

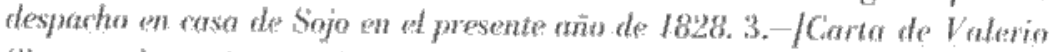
Siersa e Juan Agustín Céán Bermádes en relación con un fardo de libros de la Reral Afadrmia de la Histemin y respuesia de ésted Mso. $214.50^{4}$

S. XIX, I legajo, $220 \times 15.5$ ram. (varios lamaños).

g) Poemas de Manuel Ramón Santurio y otros:

57. [SANTURI0, Manuel Ramón:] Soneto a don Juan Cean (*Naturaleza absorta en este día / contempla al Precursor que del futuro...*)

S. XVIII (24. de junio de 1783). 1 h., $205 \times 140 \mathrm{~mm}$.

Este poema es idéntico al que obra en el Mss. 3804, f. 147 (V. Inventario General de Manuscritos de la Biblioteca Nacional ... X); ha sido reproducido por Clisson Aldana, Op. cit., p. 402.

Mss. $214.56^{10}$

58. SANTURI0, Manuel Ramón: A mi S." D." Manuela Comas. Los dias. /Hoi 1." de Enero de 1788/ (Oda: Un nuevo sol asoma por oriente, / Manuela, y en tu dia ...*)

S. XVIJI. $6 \mathrm{~h}$. útiles, $230 \times 190 \mathrm{~mm}$.

Este poema es idéntico al que obra en el Mss. 3804, 1. 139-142; ha sido reproducido también por Clisson Aldana en las p. 399-401.

Mss. $21458^{10}$

59. G.F.R.: A Juan Cean Bermudez, benemerifo escritor sobre las Nobles Artes y Bellas Letras. (aDocto Cean, del sabio Jovellanos / Discipulo y alumno en otro tiempo: ...*)

S. XIX. I h., $295 \times 210 \mathrm{~mm}$.

Es, según indira el autor, traducción libre de una composición latina de Casimiro Gómez Orlegá.

Mss. $21458^{17}$

60. [GOMME ORTEGA, Casimiro:] Ad Joannem Cean Bermulez, Clariss, in Historiae Academia Sodalem, Epigramma. (*Belgica Pisa, dono mihi quae modo miltis / Et sapida et stomacho grata fuére meo ...*)

S. XIX. 1 h., $205 \times 150 \mathrm{~mm}$.

Mss. 2] $4.56^{12}$ 


\section{PRÓLOGO PARA CUANDO SE IMPRIMA}

\section{ESTA OBRA}

Si es justo y muy debido, que el editor de cualquiera obra dé cuenta de quién fue su verdadero autor y de los motivos que tuvo para publicarla, ninguno estará más obligado a cumplirlo que el que diere a luz las Noticias de los arquitectos y arquitectura de España, por ser su materia nueva, curiosa e interesante en el reino, por el buen crédito de quien las escribió, por el juicio, crítica y erudición con que están escritas, por el ansia con que todos las desean leer, desde que las anunciaron más hace de veinte y cinco años, por el celo, esmero y tesón que se puso en publicarlas y aumentarlas y por las extraordinarias circunstancias que precedieron a su publicación.

La primera noticia que tuvo el público de esta apreciable obra se debe al erudito D. Gaspar Melchor de Jovellanos en una de las notas con que ilustró el elocuente elogio del célebre arquitecto D. Ventura Rodríguez, que había pronunciado en la Real Sociedad de Madrid el día 19 de enero de 1788, y que imprimió en esta corte el año de 1790. Después de haber referido en pocas y precisas palabras su mérito y perfección, concluyó diciendo: «Mientras nos dolemos de que la nación carezca de esta preciosa obra, que un día le hará tanto honor, queremos tener el consuelo de anunciársela anticipando al público tan rica esperanza, y al autor este sincero testimonio de aprecio y gratitud, a que su aplicación y talentos le hacen tan acreedor"; pero sin manifestar su nombre, sin duda por no ofender su modestia.

La Providencia, que vela sobre la conservación de lo que es bueno y útil en la república, y el tiempo, que todo lo descubre, dispusieron medios, no comunes, para sacar esta obra de la obscuridad en que su recatado autor la tenía sepultada, para manifestar su nombre y para adicionarla con documentos fidedignos. Se necesita vagar de parte del que haya de extender la relación exacta de estos medios, y del modo con que se llenaron los tres objetos propuestos. El editor que le tiene ahora 
muy grande (gracias a los que se le proporcionaron) temeroso de perder en adelante tan buena coyuntura, se adelanta a trabajar esta exposición antes que llegue a publicarse la obra. También se necesitará paciencia de parte del que la leyere, porque será demasiado larga para Prólogo; pero como contendrá muchas y exquisitas noticias, conducentes a la historia literaria de España y a la de las bellas artes, la indulgencia del lector no transpasará los límites de la justicia.

Estando desempeñando en Sevilla el año de 1797 Dm. Juan Agustín Ceán Bermúdez la comisión que el Sor. D. Carlos IV le había conferido en 1790 de arreglar y dirigir el archivo general de Indias, que se acababa de establecer en la casa Lonja de aquella ciudad, fue nombrado oficial de la Secretaría de Estado del Despacho de Gracia y Justicia de Indias en consideración al mérito y distinguidos servicios que había contraído, por espacio de siete años en la misma comisión. A poco tiempo de haber llegado a Madrid visitó al Sor. D. Eugenio Llaguno y Amírola, no con mo a jefe, pues pocos meses antes había dejado de serlo, sino como a un amigo, a un señalado literato, y a un distinguido aficionado, inteligente y protector de las bellas artes. Entre los diferentes puntos, que se trataron en esta prinera visita, fue el de los progresos gue iban haciendo las nobles arles en España; y como tl Sor. D. Eugcnio estaba enterado de que Cé́n Bermúdez había trabajado un Diccionario histórico de los profesores de las mismas artes en el reino, le preguntó por él con ansia de verle y examinarle; y habiendo satisfecho su curiosidad en la segunda visita, quedó muy contento y complacido de algunos artículos que leyó.

Pero como hubiesc visto que el Diccionario no comprendía a los arquitectos, manifestó sentimiento por la predilección con que miraba a esta profesión sobre las demás. Reparado algún tanto, pasó a olra pieza, y a poco rato volvió con un libro en folio, manuscrito, todo de su letra; y dijo a Ceán Bermúdez: «aquí tiene Vm. sobrados materiales para poder formar artículos de arquitectos españoles, e interpolarlos en su Diccionario». Recibió con gratitud el M.S. pero quedó sorprendido al leer el título, pues conoció, que el Sor. Llaguno era el verdadero autor de la obra que el Sor. Jovellanos había anunciado diez años antes. *No señor (le regpondió con firmeza), jamás cansentiré en que se desordene por mi causa una obra cronológica, tan preciosa, de cuyo mérito está enterado el público, y espera con ansia su impresión*. Fueron fuertes y largos los debates que hubo entre los dos, de generosidad y franqueza por una parte, y de gratitud y respeto por la otra; pero habiendo vencido la delicadeza y obstinación de Bermúdez, se quedó el Sor. Llaguno con su m.6. y el Diccionario se imprimió el año de 1800 sin incluir a los arquítectos.

Ya había fallecido entonces este ilustre y sabio escritor con el sentimiento de no ver impreso el Diccionario; pero pocas horas antes de espirar quiso dejar a su autor una prueba, nada equívoca, del afecto que le profesaba, y del aprecio en que 
tenía su trabajo de publicar las glorias de la pintura y escultura españolas, dejándole el dechado de las de la arquitectura, que el mismo Sor. D. Eugenio había escrito, seguro de que ninguno podría apreciarle más que él. Llamó a uno de sus albaceas, y le dijo: «En tal sitio está un libro m.s. de mi puño intitulado, Noticias de los arquitectos y arquitectura de España, entréguele Vm. a D. Juan Ceán Bermúdez, con los borradores, documentos y correspondencias que le acompañan para que haga de todo el uso que tenga por conveniente».

El placer que tuvo al verse dueño y heredero de una alhaja para él inapreciable, fue tan grande, como el sentimiento de haber perdido un sujeto que tanto le amaba, y no atinaba con el medio de corresponder a tamaño beneficio. Leía y volvía a leer toda la obra en ratos, que hurtaba a las continuas ocupaciones de su penoso destino: analizaba y comprobaba los nombres y edificios de los profesores con las épocas de la arquitectura; observaba sus progresos y decadencia en cada una; y admirado del tino, prudencia y crítica con que el autor todo lo había acordado, meditaba a todas horas el modo de aumentarla con otras curiosas e importantes noticias, que el mismo Ceán Bermúdez había hallado cuando buscaba las de los pintores y escultores para su Diccionario; y considerándose obligado por gratitud a sacarla a la luz pública, no encontraba recurso alguno para verificarlo, entre el bullicio y atuendo de la Secretaría.

Pero aquí segunda vez de la Providencia. Leamos sin fastidio, y admiremos sin dolor los medios de que se valió para sacar al editor de este destino, para llevarle al centro de su tranquilidad, y proporcionarle tiempo y lugar a fin de poder conseguir sus deseos.

Eran andados más de tres años después de la muerte del Sor. Llaguno, del nombramiento y continuación de Ceán Bermúdez en la Secretaría de Gracia y Justicia de Índias, y de la separación del Sor. Jovellanos de su ministerio, retirado en Gijón, y ocupado en la educación de la juventud española, cuando le sorprendieron en su lecho la madrugada del 13 de marzo de 1801, y le condujeron pública y escandalosamente a la isla de Mallorca, encerrándole en la Cartuja de Valdemuza, cuya desgraciada historia es bien sabida y sentida de todos los buenos de dentro y fuera de España; y cuando a los tres meses siguientes de esta tropelía fue trasladado Ceán Bermúdez a Sevilla a dirigir y ordenar otra vez el archivo general de Índias, no porque allí fuese necesario, sino por haber sido la persona de más estimación y de la mayor confianza de Jovellanos.

Establecido segunda vez con su familia en aquella ciudad, teatro en otro tiempo de sus estudios y de sus tareas, se dirigió inmediatamente al archivo, y habiendo hallado en su lugar otro comisionado, y visto que el sistema que se seguía en el arreglo de los papeles y en la formación de los inventarios y diccionarios era el 
mismo que el propio Cén Bermúdez hahía establecido once años antes con aprobación de S.M. le representó, diciendo, que no siendo muy necesaria su asistencia a aquella oficina, se le dispensase de la de las mañanas, para ocuparlas en la ampliación y publicación de las Noticias de los arquitectos y arquitectura de España; lo que a vuelta de correo se le concedió, y se le hubiera concedido cuanto pretendiese con tal de no volver a Madrid, ni a la Secretaría.

Dueño de sí mismo, tranquilo, sin zozobras ni sobresaltos, acometió de nuevo esta empresa, comenzando por poner en limpio todo el m.s. del Sor. Llaguno; y a fin de conseguir más noticias con que poder ilustrarle y aumentarle, escribió a todos sus amigos para que se las buscasen en los archivos de las catedrales, de Ios monasterios, de las parroquias y de los ayuntamientos, en los protocolos y en cualesquiera otros lugares en que se pudiesen hallar, acompañándoles interrogatorios; y todos lo cumplieron a pesar de aquella sentencia, que dice: Al caído pocos guardan lealtad, y todas las puertas le están cerradas. Al contrario nunca las encontró más abiertas, porque todo el mundo tuvo por injusta y bárbara la prisión de Jovellanos, y por ruín acción al desterrar al que no tenía otro delito, que ser amado de él. Así fue que compadecidos de sus desgracias los hombres de bien, se empeñaron sin miedo en obsequiarlos. Tal es el fruto de la virtud, y tal el triunfo de la inocencia.

Pasó después a recorrer los archivos de Sevilla, y con las noticias que adquirió de ellos, compuso e imprimió en esta ciudad el año de 1804 la Descripción artística de su catedral, que mereció la aprobación y aplauso de la Real Academia de la Historia, de la de San Fernando y de los primeros inteligentes y aficionados a las bellas artes: otra del Hospifal de la Sangre de la misma ciudad, impresa en Valencia el propio año; una carta escrita a un amigo suyo, que publicó en Madrid el periódico Minerva en 1806, sobre el conocimiento de las pinturas originales y de las copios; y otra en Cádiz el mismo año sobre el estilo y gusto en la pintura de la escuela Sevillana; y sobre el grado de perfección a que la elevó Bartolomé Esteban Murillo, cuya vida sp inserta $y$ se describen sus obras*.

* Con los documentog que encontró Cé́n Birmúdes en esta últimá puoca de su residenúa ris. Sevilla, en el arehivo gencral de İdias, compuso tres artículos, que aũadió a esta obra, de tres vélebres arquitectos hilláulico5, que levanturon los más famoson castillos y fortalezas de América. A causa de lenter todos cres el mismo nombre y apellido de Juan Bautista Antonelli, tardó más de dos años, pur la multitud y confuzión de los papeles, en destindar su genealogía, sus edades, sus respeclivas obras y otras cualidades, hasta que le demostraron, que el primeris y principal había sido hermano mayor y maestro del se gundo, y éste padre y maestro del tercero. Tarubién ordenó y escribió con documentos de cste archivo, que se le venían a las manos, unas Noticias exactes de las prineros expediciones que los españoles hiriseron al Waluco prra ercur especeria. Aunque los Argensolas y otrus autures escribieran sobre este asunto, podrá ser que no haya sido don tanta exactilud y certeza, porque copión las noticias de los documentos originales que obraron al ticmpo de formarse las mismas texpediciones, y porque se refieren los nombres 
Entretanto que se trabajaban e imprimían estas obras, iban llegando a Sevilla las respuestas de los amigos con las copias de los documentos que habían hallado. Y siendo la gratitud propia de un corazón sensible y reconocido a los favores recibidos, el editor se creyó obligado a publicar aquí los nombres de los que se los prestaron; pero como el recato y modestia de estos mismos sujetos no se lo hubiesen permitido, le es forzoso dejarlos en silencio por no ofenderlos. Mas no lo hará del principal, pues además de no existir ya entre los vivos, privaría a la posteridad de un ejemplo heroico del poder e influjo que tienen la amistad y la filosofía sobre las almas grandes, aun en medio de las mayores angustias y tribulaciones.

iParece increible! D. Gaspar de Jovellanos, encarcelado en la estrecha cuadra de un castillo, situado en despoblado, con centinelas dobles y una de vista, a las órdenes de un inclemente y despiadado comandante; sin otro trato que el de un criado que entraba a servirle lo más preciso en horas determinadas, y de un director espiritual, que le conhortaba en ciertos y señalados días, tuvo allí humor, paz, reposo y serenidad para ocupar su espíritu atribulado en indagar las obras de los arquitectos mallorquines, en describir sus edificios, y en trabajar largos tratados sobre estas materias.

Ya había sabido en Gijón la manda que el Sor. Llaguno dejara a Ceán Bermúdez, y en la Cartuja, que le habían retirado a Sevilla, y no dudando que tratarían de aumentarla y publicarla en aquella ciudad, quiso tener parte en este trabajo. Si no lo hizo desde luego en aquel monasterio, fue porque se había dedicado a dirigir y a acabar obras útiles y provechosas, para la comunidad. Estaba destinado el castillo de Bellver para ser el teatro de su persecución, de su triunfo y donde diese las úlimas pruebas de su saber y de sus conocimientos en las bellas artes; por lo que será más célebre en adelante entre los literatos, que por haber sido antiguamente palacio de los reyes de Aragón. Castillo que jamás se borraba de la memoria del Marqués Caballero por el temor de ser enviado a él, como él mismo decía, especialmente cuando le mandaban expedir órdenes, que después llamó injustas.

\footnotetext{
y destinos de todos los sujetos que fueron en ellas. Aún es más apreciable e interesante la certificación ràciocinada, que dio en principios del año de 1808 de un preciosísimo expediente, que acababa de descubrir entre los innumerables de aqucl archivo. Constaba de dos informaciones originales y de otras diligenciaz, relativas, la primera a las hazañas del incomparable Miguel de Cervantes Saavedra en la famosa batalla de Lepanto, y la segunda a las que ejecutó después en Argel, desde que le cautivaron los tureos hasta su rescate. Copió e insertó este expediente en la certificación, y después de haberle ilustrado con notas lo remitió a la Real Academía Española por mano del Ministro de Estado el Sor. D. Pedro Ceballos, que hizo de ella el aprecio que se merecía, por contener unas noticias tan interesantes, como ignoradas hasta entonces; y acordó que en vista de ellas se volviese a escribir otra vida de Cervantes, la que concluida será de gran satisfacción a la república literaria.
} 
Los primero que escribió el Sor. D. Gaspar en este encierro fue la 1. parte de la Descripción del Castillo de Bellver, y de sus vistas: lo segundo un Apéndice a esta primera parte: lo tercero la 2." parte de la dicha Descripción: lo cuarto una Memoria sobre la fábrica de la Lonja de Palma: y lo quinto otra Memoria sobre las lábricas de los conventos de Santo Domingo y San Francisco de Palma de la misma ciudad, que componen cinco volúmenes en cuarto grande, de papel de marca, adornados con diseños, lavados de tinta de china, que representan las plantas, alzados, fachadas y cortes de los edificios que se describen en cada tomo, e ilustrados con notas y enpias de documentos, en justificación de las obras que reficren y de la legitimidad de los profesores que las trazaron y ejecutaron.

Además escribió una carta muy larga al Editor, o más bien, un discurso sobre la arquitectura inglesa y la llamada gótica, que formó sobre el tratado Londres y los Ingleses, que acababa de publicar en París Mr. Ferri de St. Constant, y había podido conseguir en aquel castillo. Pieza muy interesante e instructiva para los que se deleitan en el estudio del origen y progresos de las bellas artes, y quieran saber el punto de perfección a que llegaron en Inglaterra el pintoresco y el grabado en dulce. Pero todavía es más apreciable una erutidísima Advertencia, como él llama, o sea una disertación, sohre la excelencia, el descubrimiento, forma, carácter y originalidad de un precioso códice, que también llegó allí a sus manos, titulado, Discurso del Sor. Juan de Herrera, aposentador mayor de S.M. sobre la figura cúbica. Como este celebérrimo arquitecto, uno de los mejores matemáticos de su liempo, se hubiest propuesto seguir en su discurso el sistema y doctrina de Raimundo Lulio, reficre Jovellanos en la advertencia, la historia del I,ulismo, su doctrina y sistema en general, y los motivos que tuvo Herrera para meterse en este laberinto. Precede a la advertencia una copia exacta del códice y de lodas las líguras geométricas, que contiene el original, perfecta y muy limpiamente escrita y ejecutadas, como los anteriores tomos, por D. Manuel Martínez Marina, discípulo del Instituto Asturiano, que salió de Gijón con el Sor. D. Gaspar para Mallorra, y le acompañó en sus trabajos**.

Estos siete volúmenes llegaron sin tropiezo uno en pos de otro, según iban saliendo de las manos de su autor, a las de su amigo Ceán Bermúdez, a pesar de las duras y repetidas órdenes y de las vigilantes centinelas, que lo impedían; porque es

** Amén de estas obras escribió otras en el castillo el Sor. Jovellanos en prosa y verso, que no pertenceen a las bellas artes; y qut lambién remitió u su amigo el editor. Se distingue entre ellas por su clegaveja y sublimidad un Epístola en verso blanco, dedicada a Bermido, nombre tomado de su apellido, sobre los veanos despos y pstulins de las hombres, en la que desengañado del mando presenta los necios desvaríos de los que intentan ligurar en él. Es el último documento moral de los muchos que le dio en sut vida, por lib que le conserva en su corazón. 
muy vano el poder de la tiranía contra el ingenioso amor de dos almas que unieron desde la niñez la virtud, la inocencia y la uniformidad de ideas.

Con tau apreciables documentos y con las muchas copias de actas de cabildos de catedrales y colegiatas, de visitas de lábricas de parroquias, de capítulos de comunidades religiosas, de eontratas hechas por arquitectos de fama, obligándose a trazar y construir los edificios, los retablos, y otros adornos, de cuentas de fábricas de iglesias, de partidas de matrimonios y entierros de profesores, y de otros instrumentos fidedignos que enviaron al Editor de Toledo, Cordoba, Cranada, Valladolid, Cuenca, Palencia, Tarragona, Barcelona, Gerona, Zaragoza, y de otros muchos pueblos de España, llegó a juntar tan erecido caudal de noticias autorizadas, que excedía al que tuvo presente el Sor. Llaguno para formar su M.S. Por lo que persuadieron algunos sabios académicos a Ceán Bermúdez a que formando una masa general de todas, y ordenándolas cronológicamente fundiese de nuevo una obra, que intitulase Historia de la arquitectura en España, remontándola a lo menos, hasta el tiempo de los romanos. Terrible tentación para los que aspiran a ser escritores originales, aunque sea ataviándose con vestidos ajenos. Pero el editor desechó con firmeza este proyecto, por ser perjudicial a su honor y a su delicadeza, pues de ejecutarle faltaria a los deberes y cotsideraciones que tiene de gratitud, de respeto y de estimación a la digna memoria del Sor. D. Eugenio, su bienhechor, conlentándose con ser un mero adicionador de las Noticias de los arquitectos y arquitectura de España, y con poner al pie del texto, que dejará siempre intacto sin ninguna alteración, las apostillas, que sean necesarias para ilustrarle, y para aclarar más el asunto.

Pero antes de referir el sistema, que el editor ha adoptado para colocar sus adiciones, parece conveniente que explique el que eligió el Sor. Llaguno para su obra. La dividió en tres secciones: trata en la primera de los edificios que se construyeron en España desde que D. Pelayo comenzé a reconquistar el reino en Asturias, hasta fines del siglo XI: describe sus formas y manera de edificar entonces; y da razón de los profesores que trazaron y construyeron algunos de ellos: Cuenta con mucha erudición en la segunda el origen de la arquitectura, llamada vulgar e impropiamente gótica, cómo y cuándo se introdujo en España, y cómo permaneció su uso en ella hasta fines del Siglo XV y principios del XVI: procura describir sus edificios sin olvidar los nombres y demás calidades de los artistas, que pudo adquirir, y trabajaron en aquella edad. Y refiere en la tercera la resurrección paulatina de la arquitectura grecorromana, desde esta última época, sus progresos, su elevación, su decadencia, y su total abandono en principio del siglo XVIII, dando fin a la obra en 1726, por cuyo tiempo se incendió el palacio viejo de Madrid. Subdivide las secciones en capitulos, que casi siempre son otras tantas vidas de arquitectos: pero nada dice de la arquitectura arabe, que reinó muchos años en Lspaña hasta 
fines del siglo XV, siendo así que aún se conservan en ella trozos y edificios enteros, que publican su carácter, y aún inscripciones que manifiestan los nombres de sus profesores. No hay otro modo de calificar el tino, exactitud y erudición con que está escrita esta obra, que con las expresioney de que se valió, el que primero la anunció al público: «Los hechos (decía) y memorias más exactas, las relaciones más fieles y completas, los juicios más atinados e imparciales se encuentran allí escritos en un estilo, correcto, elegante y purísimo, apoyados en gran copia de documentos raros y auténticos, e ilustrados con mucha doctrina y exquisita erudición*.

Después de haber copiado exactamente Ceán Bermúdez todo este M.S. como se ha dicho en otra parte, puso en lo alto del margen de cada plana el año que iba rigiendo en la relación, comenzando por el de 720 , en que principia y acabando en el de 1726 en que concluye: pasó de seguida a ordenar todas las noticias que había adquirido de dentro y fuera de Sevilla, y habiendo extendido cada una de ellas en relación, en forma de artículos, y en hojas sueltas, puso también en los márgenes los años que las correspondían. Hecho esto las fue colocando en las lagunas que dejó el Señor D. Eugenio en su obra, distinguiéndolas con el título de Adiciunes. Resulta de este método: 1." dejar íntegro el texto del M.S.: 2. llevar seguida y constante la cronología, desde su principio hasta el fin: y 3." señalar cuál es el trá bajo del Sor. Llaguno y cuál el de D. Juan Agustín. Quedaron otras papeletas cuyas materias y profesores eran los mismos que los contenidos en algunos capítulos del M.S.; pero como se diferenciasen en los años o en otras notables circumstancias, se pusieron al pie de cada uno, como glosas para mayor ilustración.

Como muchas de las noticias adicionadas se sacaron de locumentos originales, se refieren en su exposición al apéndice de cada tomo en que están copiados; de manera que muchos de los principales arquitcctos y sus mejores obras se comprueban con testimonios in'refragables, que la crítica más escrupulosa no puede desechar. Trabajo prolijo, que solamente el empeño y la paciencia del editor pudieron llevar al cabo, con la particularidad de haberlo escrito todo de su puño.

Aún le restaba que hacer para la cabal conclusión de esta obra. Se lee en la portada del M.S. en seguida del título, una nota de letra del Sor. Llaguno, que dice así: En el principio de estas Noticias se debe poner una introducción, que no está hecha». Y en otra parte escribió: «Precederá un Discurso sobre la arquitectura, que está por hacer*. Nuevo empeño para el editor, que resistió mucho tiempo, por el temor de considerarle superior a sus fuerzas. ¿Pero a quién había de encargarle? ¿Por ventura son muchos en España los sujetos dedicados e instruidos en estas materias? Solamente el que seguía encerrado en el castillo de Bellver podría desempeñarle, y lo hubiera hecho con mucho gusto, si hubiese terido a la mano Ios auxilios, que tenía el Editor, por lo que se vio en la necesidad de emprenderle. 
Después de hablar de las ciencias y conocimientos con que debe estar adornado el arquitecto, dividió Ceán Bermúdez su discurso preliminar en diez épocas. Presenta en la primera el origen de la arquitectura, y el carácter y forma de las obras que construyeron en España sus primeros pobladores. En la segunda habla de la manera de edificar de los fenicios y de otras naciones, que vinieron acá, incluso los cartagineses. Se detiene en la tercera a referir cuál fue la de los romanos; recorre rápidamente la España, describe muchas ruinas y monumentos, que todavía se conservan en ella, y se remite al apéndice, donde copia muchas inscripciones de arquitectos romanos, que trabajaron en el reino. Señala en la cuarta época los pocos edificios, que nos han quedado de la arquitectura verdaderamente gótica, por ser la que usaron acá los godos, y también copia en el apéndice alguna otra inseripción de aquel tiempo. La quinta es más interesante porque trata de la arquitectura árabe, de su fisonomía, de varias obras que los moros erigieron en la península, y de los arquitectos que las construyeron, comprobadas con inscripciones, traducidas y copiadas en el mismo apéndice, donde también se halla un índice alfabético, bastante largo, de voces técnicas de esta profesión, de origen árabe, que todavía se usan en algunas provincias del reino, especialmente en Andalucía, trabajado por el editor para demostrar el influjo que tuvieron los moros en nuestra arquitectura. Trata en la sexta de los edificios que levantaron los primeros reconquistadores en Asturias, de los cuales aún se conservan algunos pobres y pequeños, de sus formas mezquinas, y del modo que tuvieron de construirlos. Se extiende en la séptima a describir por partes la arquitectura, llamada vulgarmente gótica, explicando su gallardía, su dignidad, sus miembros y sus adornos. Por haberse conservado este género de arquitectura en el reino más de tres siglos, y por haber sido la época en que se construyeron los mayores y más principales templos, es una de las más importantes para la historia del arte. No lo son menos la octava y la nona por tratarse en ellas de la resurrección de la antigua arquitectura grecorromana, de su elevación, y de su total decadencia. En fin dice en la décima cómo volvió a recobrar su esplendor con el establecimiento de la Real Academia de San Fernando, y con las luces de sus sabios directores; y concluye el discurso, recapitulando lo expuesto en las diez divisiones. Sea el que fuere su mérito, mereció el autor, que habiéndose leído con general aplauso en la Real Academia de la Historia, pasase de la clase de individuo corresponsal a la de académico supernumerario.

La copia integra del M.S. del Sor. Llaguno con las notas al pie, del editor, sus muchas y largas adiciones, interpoladas en sus respectivos y acomodados lugares, la copia de los uumerosos y dilatados documentos del apéndice y el extendido discurso preliminar formaron un volumen demasiado abultado e incómodo para manejarse; por cuyo motivo y porque Ceán Bermúdez seguía recogiendo más noticias 
para aumentarle, juzgó ser muy conveniente dividirle en cinco tomos. Nurevo empeño, molesto y fastidioso para el que haya de emprenderle. No importa: el editor. le acomete con su incansable pluma, sin permitir que otra alguna le ayudase.

Copia segunda vez en el primer tomo con ímproba limpieza y corrección el discurso preliminar, la parte del texto del M.S. con sus notas y adiciones correspondientes, que comprende las dos primeras secciones, y empieza el año de 720 hasta el de 1524; y al fín los documentos pertenecientes a esta época en su respectivo apéndice. Iso mismo ejecuta en el segundo tomo, que comienza con la secrión tercera, desde 1525 hasta 1560 ; en el tercero desde $156 \mathrm{I}$ a 1582 ; en el cuarto desde 1583 a 1613 ; y en el quinto desde 1614 hasta 1734 en que se quemó el palacio viejo de Madrid, y concluye la obra. Es de advertir que para cada tomo hizo tres indices alfabéticos de lo que contienen. El primero de Ios nombres de los arquitectos; el segundo de los pueblos en que existen sus obras; y el tercero de los documentos copiados en su apéndice.

No había concluido este molestísimo entretenimiento cuando recibió Ceán Bermúdez una real orden del Sor. D. Fernando VII que acababa de subir al trono, por abdicación de su padre el Sor. D. Carlos IV, fecha en Abril de 1808, mandándole volver a la Secretaria del Despacho de Gracia y Justicia, con la antiguiedad que le correspondía desde su primer nombramiento en 1797. Fue grande la sorpresa que le causó la inesperada gracia por no haberla solicitado; y si por ser honrosa le llenó de satisfacción, no dejó de causarle sentimiento, considerando el destino, a que volvía, tan opuesto a su tranquilidad, y que le impedía poder concluir una obra, en que tenía puestos, como se suele decir, sus cinco sentidos; y que por haberla prohijado deseaba concluirla y publicarla a toda costa, para dar un testimonio de aprecio, gratitud y respeto a la buena memoria de su verdadero y primitivo autor.

Salió de Sevilla D. Juan Agustín el día 20 de mayo de 1808 con toda su dilatada familia, rodeado de sustos y presentimientos, y pasó en la Mancha por medio del ejército de Dupont, que le robó y estropeó parte de su equipaje, especialmente libros y pinturas, entre ellas, el retrato de su padre, que él mismo Ceán Bermúdez habia pintado, y el del célebre pintor de Cámara D. Francisco Goya, hecho de su mano. El sentimiento de estas pérdidas se templó con saber que el Sr. Jovellanos estaba libre en el continente, y que habían escapado de la luria francesa los manuscritos del Sor. Llaguno y todo lo que el editor había trabajado en el asunto.

Desde que entró en Madrid comenzó a padecer su espíritu con las maquinaciones de los que se ppusieron a que gozase la antigüedad que el rey le había restituido; y con las intrigas y asechanzas de los mismos, que más adelante armaron para trasladarle, como le trasladaron, a pesar suyo, a un nuevo ministerio de Nego- 
cios ectesiásticos, que el gobierno intruso había establecido, ¿Quién podrá reterir la amargura que sintió su corazón todo el tiempo que permanceió en él sin poder huir, ni volver a Andalucía, por estar rodeado a Lodas horas de espías y testigos, que no le perdian de vista? ¿Quién los insultos, las persecuciones y los improperios que toleró por proteger a los buenos eclesiásticos, por sostener el culto de los templos, por abastecer los destruidos de vestiduras y vasos sagrados, por consolar y tocorrer a las religiosas, por dirigir y amparar a los prelados y sacerdotes perseguidos? No es éste el lugar de bacer su apología, más adelante se la hará su causa, sino de presentar muy en bosquejo los motivos que le impedian de hacer mayores progresos en la obra de los arquitectos.

Sin embargo de tantos afanes y de tan graves y peligrosas oeupaciones, procuró en los cortos ratos que le dejaban para su descanso, concluir lo que había comenzado en Sevilla a poner en limpio. Y no pudiendo examinar por sí mismo los libros parroquiales de Madrid, que le proporcionaban el frecuente trato, que por su empleo tenía con los Curas, lo encargó a un amigo suyo, que sacó de ellos muchas e interesantes noticias de matrimonios y fallecimientos de ilustres profesores, con que logró enriquecer su obra. Fntonees fue cuando, como ya se ha dicho arriba, la Real Acadenia de la Historia aprobó et discurso preliminar; y cuando mandó imprimir en sus Memorias el elogio del célebre arquitecto Juan de Herrera, que: lo había encomendado, y por t que volvió a ser ascendido a la última clase de Académico de número.

Más que todo esto fue el baber emprendido en tan críticas circunstancias, y en la más dolorosa sifuación en que se había visto hasta entonces, con la noticia de la infausta muerte de su amado Jovellanos, y con la vista de la inesperada de su hijo primogénito D. Manuel Ceán Bermúdez, joven de veinte y cinco años, sacerdote de dicz meses, que fue víctima de su caridad con los pobres enfermos a los cuatro días de haber caído en cama. AAt!... el haber emprendido la composición del sexto tomo, que ha de ser el complemento de la historia de la arquitectura de España hasta nuestros días.

Empicza en el año de 1735 en que acabó el quinto. Se refiere en su prólogo el sstado en que se hallaba entonces esta profesión en el reino; y dividido en capítulos, que son otras tantas vidas de arquitectos, cuyo número no está aún determinado, porque se ignora hasta dónde. llegará, aunque al presente asciende al de setenla y tres, principia el primero por la del presbítero D. Juan Lubara, abad de Selve, que vino a Madrid el mismo año de 1735 a trazar y dirigir el palacio, que se había de construir entre la puerta de los Pozos y la de Santa Bárbara. Sigue en el segundo la de su discípulo D. Juan Bautista Sathetti, que trazó el que está en el mismo sitio, que ocupaba el anciguo; y después las de los demás profesores, como son D. Juan Medrano, D. Santiago Bonavia, D. Francisce Cartier trazador y director de 
lat olira del monaterio de las Salesas reales. I). Virgilio Ravaglio, qute hizo los planes del palacio de Riofrío, D. José Hermasilla los del Hospital generat el códebre D. Ventura Rodrígue\% restaufador del buen gusto, sencillez y decoro. 1). Diego Villanueva, y su harmano D. Juan, D. Franciaco Sabatini, 1). Carlos La Meaur, D. Prdro Arnal, hos discípulos de estos maestros, y los de las Academias de S. Fernando y de b. Carlos con otros profezores. los ruales fon wus obras, deseritas an sus respectivos capítulos, elevaron nuestra arquitecura al grade de perfeceion en que hoy se halla

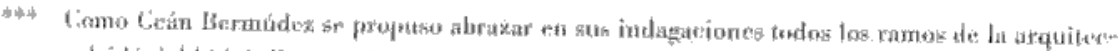

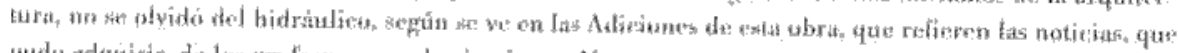

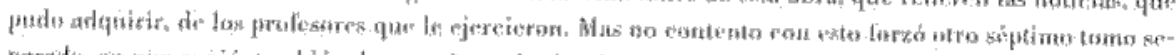

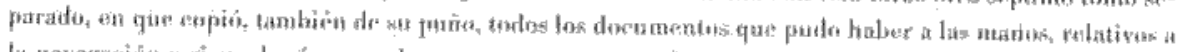

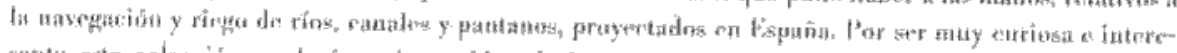

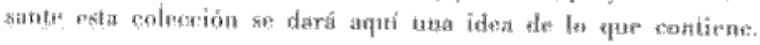

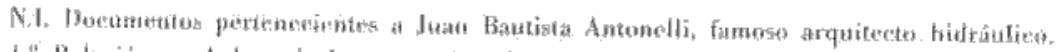

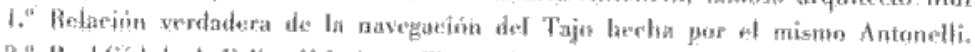

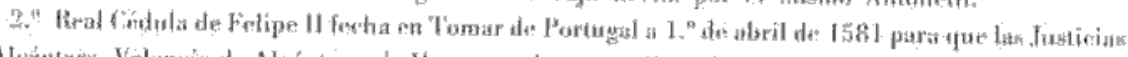

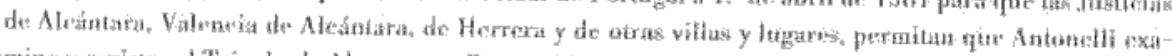

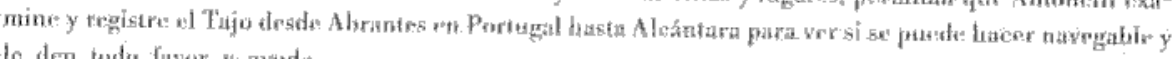
In der mola fasor y ayuda.

3." De cómu hntonelli ac partió en un barco por al Tajo arriba, para Alcántara y velvió [ror t. mismo riol a Abrintes.

4." Relación de la anterior navegación, que es de 24 leguas, presentada por Antonelli al roy eo Tou mas, a 20 de mayo del propio año.

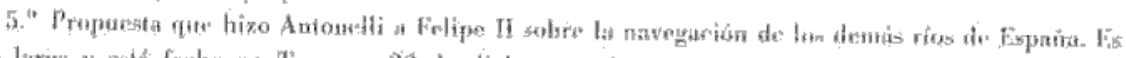

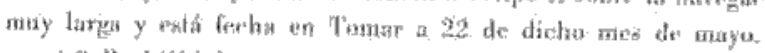

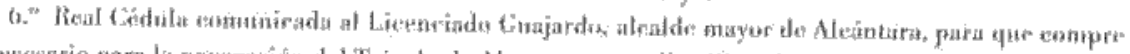

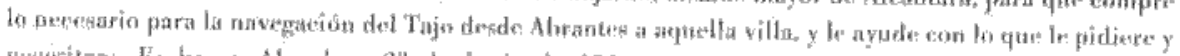

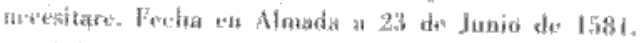

7." Oira real céalula sobre! lo mismo a Jos Conscjos y demás justicias de Castilla: duda ean igual tocha mn Almada.

8." Relación det viaje o navegación que hizo Antonelli por el Taja desde Lishoa a l'oledo, y drosdo

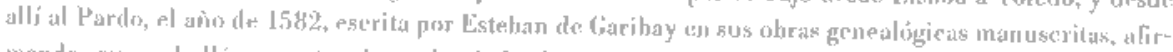

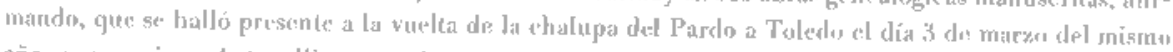
añn, y que vio a Ancomolli proserguir su viaje: hasla Lisbua.

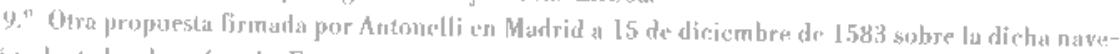
gavion de todos los ríns de Fispaña.

10)" Relacion del viaje que hizo el año de 1.584 Felipe 11 , cen el príncipe y sus hijas las serenísimas

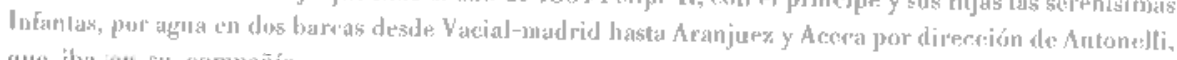
que iba on su compañía.

11." Rical provición del enosejo, enmunicada a las Justicias del reino para que diesen favor y ayuria

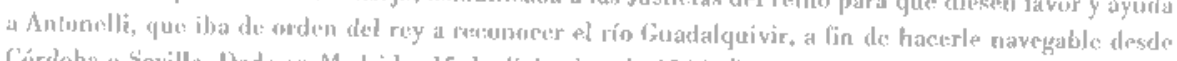

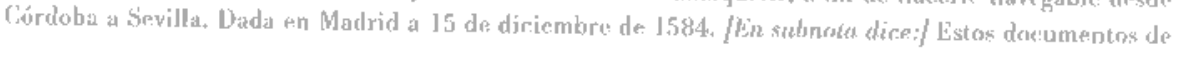


Esta era la ocupación del Editor en Madrid durante el gobierno francés, alternando con la de sostener el culto de la religión y defender los derechos de la Iglesia. Fuéronse los enemigos a Valencia, y Bermúdez, que jamás había desamparado la corte, desde que volvió de Sevilla, sin embargo de las varias salidas que hi cieron, confiado en su buena conducta, se quedó en Madrid con aplauso de todos los que le trataban y conocian. Pero cuando gozaba la tranquilidad de su conciencia y esperaba el premio de sus trabajos y de sus extraordinarios servicios (iciún

Antonelli no están en la colección, sino en il Apéndice del tomo III de esta obra, en el que se refiere la vida y obras del dicho Antonelli.

1I. Parecer que dio Leonardo Turriana, ingeniero mayor de Portugal, sobre la navegación del rio Guadalete al Guadalquivir, y a Scrilla. Fecho en Madrid a 17 de julio de 16,24.

III. Discurso breve con que se prueba la posibilidad de sacar agua del río Júcar para los llanos de Quart, Liria, Murviedro y otros. Se copió de un impreso en Valcneia año 1628 , que ya es muy raro.

IV. Memoria que escribió Jaime Fanegas al gobernador de Laragoza sobre la madera, que se puede sacar en los montes Pirineos de Aragón, para fabricar galerus y hacer muchas inastes y entenas de ellos.

V. Canal de riego del río Essera en el reino de Aragón.

VI. Memorial que los coroneles D. Carlos y D. Fernando de Grunembergh ha dado a S.M. en 1668 tocante a la proposición que tenían hecha de rendir navegable a Manzanares desde la otra parte del Pardo hasta Toledo. Está impreso y tiene un plan del Canal.

VII. Relación e informe que dieron Luis de Lin̄ản y Vera, ingeniero y maestro mayor de haccr bascos del Buen Retiro, y Felipe Busignac y Borbón, maestro arquitecto de lábricas de los cuatro Brazos de las Cortes de Aragón, sobre si se podría hacer ravegable el río Ełro desde Zaragoza hasta el Mediterráneo, y acerca de elegir un puerto en este mar para el comercio de aquel reino: a cuyo efecto salieron embarcados de dicha ciudad por el Ekiro, el día 27 do Julio de 1677.

Tortosa.

Los Allaques.

Pucrlo de Vinaroz.

Gasto que se discurre, que se ofrecerá en hascr navegable el río Ebro.

Reparos sobre la navegación del Ebro.

VIII. Navegación de algunas ríos y canales de Cataluña.

1. ${ }^{\circ}$ Río Segre.

2." Río Francoli y canal de Urgel.

3." Río Ter y canai de Bañolas.

IX. Canal navegable desde el Mar Mediterráneo al Océano Cantábrico, continuando el proyectado del reyno de Aragón, cruzando cl de Navarra y la provincia de Guipúzcoa por los ríos Arga y Oria, unidos por varios manantiales y depósitos de agua en la altura de Lecumberri.

X. Canal de Aragón.

1. Historia de la Acequia Imperial; escrita en Bocalreal y en junio de 1788

2. Razón de las obras del canal de Tauste desde últimos de septicmbre de 1780 hasta agosto de 1787. 
engañosa es la confianza de los hombres! iCuán vana y deleznable su prospridad!) tue sorprendido a la una de la noche de 26 de Septiembre de 18.12 por uno de los jueces, que componían la Junta, llamada de Vigilancia, acompañado de escribano y alguaciles, que después de haberse apoderado de todos sus libros y papeles, le lievaron a una caballeriza del Buen Retiro, rodeado de más de cuarenta soldados, como si luese un homicida, o un delincuente de lesa patria, según apellidatan entonces cl mayor delito.

XI. Camal y Pantanos dis Icorea:

Obras aeresorias.

Otras uhras alecesorias,

Camino ite: Aguilas.

Comductín de la Fuente du Águilas.

Obras agrergadas.

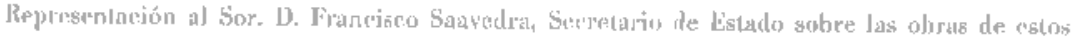
Pantanos, [erha en Madrit] a 31 de mal\%o de 1798.

Notat del desalatre de esto Pantano en 30 de abril de $180^{2}$.

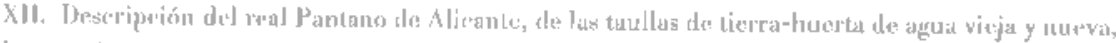
y de las que riegan por el azad musvo, Uamado de S. Juan, que está construido hacia el curso de las aguas.

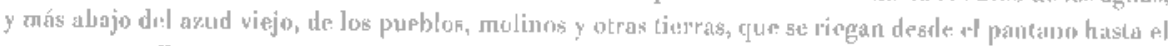
nuevo alzud. listerita pors D). Jospf Cabcant en 180.5.

XIll. Otras documentos sobre la navegarión de! Tajo y sobre el ranal de Wanzanares.

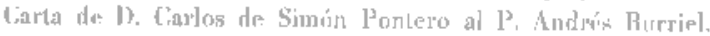

Respursla da: Burriet a P'ontero.

XIY, Relación de los canales de Cabtilla, según corsta de lus Memorias que existen en su Jirecciun.

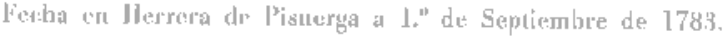

XV. Relación del estado en que se hulla la navegación dtal ró Cuadalquivir desde Sevilla al onéano.

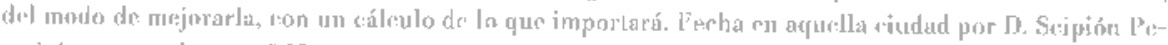

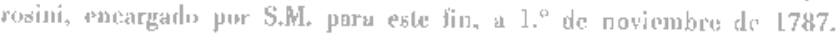

XVI. Canal de Guadarramb.

Ofirio del Ministerio de Harienda al Sor. Savedra. Sén IJdelouso 11 de agosio de 1796. Informe rle D. Finiuriseo Saavedra. Madrid 14 de septienture de 1796.

1. Partr.

2. ${ }^{\text {P Paltr. }}$

3." Parte.

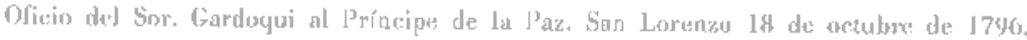

Olicio ded P’ríncipe de la Paz \& D. Pedro Vareda. San Jorenzo 12 de noviembre de 1796.

XVII. Mrmaria demoblraliva de Ja probubilidad, n seguridad speculativa, que prestenta el prensamisuto de Camales y sus undiciones; presentada en Aranjuez al Sor. IJ. Carlos IV.

1. Memorial al rey ate los dinques de Medinaceti, Infantado y Osuna, y del marequés de Asturga, feetho en Mudrid a 23 de Febrero de 1797 , obligándus. por una compaña y bajo ciertas condiriones a sonstruir canales. 
Allí pasó el resto de la noche en una total obscuridad, en pie, sin ningún arrimo, sobre el fétido excremento de los bien mantenidos ingleses, que le custodiaban y a otros treinta y seis reos, que por el sólo hecho de haberse quedado en Madrid y de no haber seguido con los franceses a Valencia, ya no lo eran. Pasados veinte días apareció el Juez, que le había preso, a tomarle declaración, sin embargo de que la Constitución, que acababan de jurar, mandaba fuese antes de las veinte y cuatro horas: tal era el ejemplo de los que velaban sobre su observancia. El resultado de esta diligencia fue hlamar en el Diario a todos los que tuviesen que deponer contra Ceán Bermúdez en el término de nueve días: no pareció más que uno, a quien no quisieron oír, porque hablaba en su favor. Con semejante imparcialidad se empezó la justificación de una causa, que llamaban de Infidencia; y es de advertir, que no consta en el proceso esta convocatoria, sin duda por no haber producido nada de lo que buscaban, por lo que pidió más adelante el reo, que se

3. Treinla y dos artículos, que expresan los medios y condicjonces necesarios para formar una compañía, que emprende la construcción de varios canales para la navegación interior del reino.

3. Manifestado el prospecto del proyecto, divídese la Memoria en 4 partes.

1. Utilidad del pensamiento.

2." Probabilidad de la cjecución.

3." Los medios propuestos son sulicientes para llevar a decto el proyecto.

4." Reflexiones relativas al mismo plan, y algunas ideas para su extensión en to sucesivo.

4. Carta de D. Francisco de Saıtvedra, al duque de Osuna, devolvićndole el anterior papel.

5. Carta del Duque de Osuna a Satuedra, acompañándole una copia del anterior papel.

6. Plan circunstamiado, que denota las leguas que se hacen en cada canal, y en todos ellos en cada un año de los veinte y quatro; cl total del cosle que tienen éstas, y el pago de los capitales y téditos: cl total de entradas por ramos de arbitrios: producto de canales, préstamo, y juego; y el solmante con que se puede contar de un año para otro.

7. Proywdo in wal iteireto solure canalcs, que debe dirigirse al Consejo de Castilla, mandando erigir una stih superistudeneits de Catales de navegación y de riego, reuniendo en ella todos los fondos que laya diapersasen obras sle esta clase, y los que hubiere de haber en adclante. Consta de 34 artículos.

XVIII. Razón de 108 antiguos canales de Ribarroja al poniente de Valencia y a tres leguas del río Turia. Dada por D. Juan Sánches Cïsieres en Valencia a 10 de Oetubre de 1807.

En el Apendice det tomo III de esta obra de leu Arquticetos están ropiatas varias resales cédulas, fe-

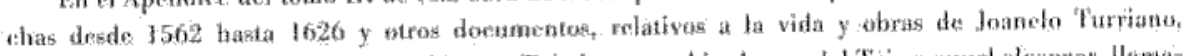

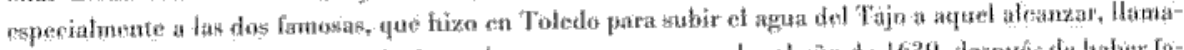

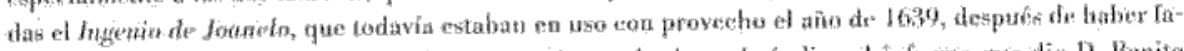
llecido sil antor en et de 1575. Tambián se copia en al mismo Apendien el informe que dio D. Benito Bails w 1777 at bibliotecario mayor D. Juap de Santander selure uno M.S.S. que este habia hultado, y

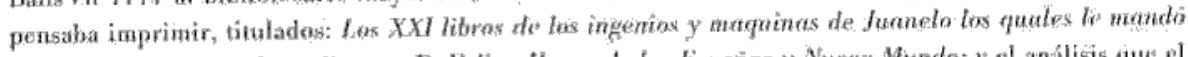

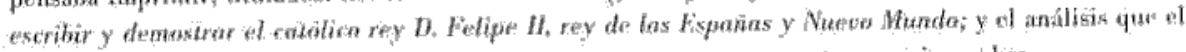
misme Bails hizo de cada uno de tos cines tomos, que componen tar prexioga bhra. 
insertase en él: el Diario. Después de treinta y cuatro días de reclusión en el Buen Retiro, mandó el tribunal restituirle a su casa hasta nueva orden, y que le devolviesen las llaves de todos los libros y papeles. Así lo ejecutó el escribano, que le chupó lo que no debía haslá que se sentenciase la causa.

Volvió de Valencia el Gobierno intruso a dominar en Madrid y con él nueva persecución contra el editor, porque los males andan asidos de ordinario unos con otros, y el fin de un desastre suele ser muchas veces principio de mayor desgracia. Inmediatamente le formó causa el Ministro de policía por no haber seguido a aquella ciudad, por la amistad estrecha que tenía con el Vicario Eclesiástico de Madrid, por haberle dirigido y aconsejado ex sus acertadas providencias, por la protección que prestaba a los clérigos y a los religiosos, adictos a los patriotas, por haber entregado al Gobierno español las llaves del depósito de las vestiduras y var sos sagrados y las del Ministerio de Negocios eclesiásticos, y por otros motivos que le tenían probados. Pero en este tiempo evacuaron los franceses por última vez a Madrid, donde se quedó Bermúdez, a pesar de lo mal que le había tratado la Junta de Vigilancia, guardando en su casa el encierro que le había ordenado. Tres meses estuvo en él, venerando los medios de que se valía la divina Providencia para su purificación espiritual, que es la que debe preceder a la política, y dándole gracias por haberle traído a aquel estado, en que conociesé y apreciase tamaño beneficio. En medio de estas consideraciones y de como el mundo juega con los destinos de los hombres, procuraba distraerse con las Noticias de los Arquitectos, que volvió a emprender con tranquilidad de espíritu. Se entretenía en tan útil e inocente diversión, comprobando y perfeccionando lo que tenía trabajado, cuando el día 27 de aguslo de 1813 le llamó a su casa otro Juez para tomarle otra declaración, o para concluir, como él decía, la que había dado el año anterior en el Buen Retiro, y para que se defendiese en la causa que allí se le había comenzado, y que acababa de llegar a sus manos.

Se presentó el Editor a la hora señalada con la serenidad y franqueza que le inspiraban la inocencia y la satisfacción de su proceder; y habiéndose finalizado la declaración, le mandó el juez que prosiguiese en el encierro de su casa en las mismos términos que le había guardado hasta aquel día, en el que Ceán Bermúdez continuó trabajando en la obra de los Arquitectos. Se evacuaron las citas, que resultaron de la declaración; se pasaron oficios al Rdo. Obispo auxiliar de Madrid, al Vicario eclesiástico, al cura de la parroquia, al confesor de Bermúdez, al Bibliotecario mayor de S.M., al Receptor de la Capilla real, al Penitenciario del real monasterio de la Encarnación y al P. Provincial de los Aguslinos calzados. Manifestaron estos respetables testigos de vista los justos motivos que había tenido D. Juan Agustín para no haber ido a Cádiz, para quedarse en Madrid, y por haber aceptado el destino de oficial mayor del ministerio de Negocios eclesiásticos, destino de ri- 
gurosa escala, por la analogía con Gracia y Justicia, y porque Bermúdez era el olicial más antiguo que había quedado en Madrid.

Algunos de los testigos confesaron que ellos mismos se lo habían aconsejado, y la satisfacción que tuvieron después al ver cumplida su provisión, por lo bien que había desempeñado tan arriesgado empleo en favor de la iglesia, amparando a los Sacerdotes beneméritos, y defendiéndolos de las acusaciones y asechanzas con que los perseguían. Otros aseguraron que Ceán Bermúdez, no tan solamente no había solicitado la insignia de la llamada Orden de España, sino que explicaron el ardid, sorpresa y fuerza con que le obligaron a ponérsela, y el modo con que la traía. Insignia, que sin embargo de ser justamente odiada por nuestro gobicrno, no obstó para que se confiriesen tres mitras a los dignos sujetos que la habían usado contra su voluntad, como D. Juan Agustín. En fin todos los ocho testigos probaron su lealtad y fidelidad, y le creyeron digno y acreedor a ser repuesto en su antiguo empleo.

Se oyó por escrito al Alcalde de Barrio; y últimamente al Promotor fiscal, que concluyó su informe en estos términos: «Bajo esta inteligencia, lejos de pedir contra dicho Ceán Bermúdez, como se me manda y se dirige mi comisión, me contraigo a suplicar a V.S. a que incline el ánimo del Gobierno, para que con arreglo a los decretos de las Cortes en razón de los empleados, se le reponga en el que tenía cuando entró el Gobierno intruso, cortando la causa en el estado en que se halla, y condenándole en las costas por el justo modo de proceder.

El Juez en vista de este informe fiscal y de todo lo que resultaba del proceso, declaró a D. Juan Agustín Céán Bermúdez por una honrada, fiel, patriótica, pacifica y sana conducta politica y benemérito de la Iglesia española, en la estancia del gobierno intruso en esta capital, y en el empleo o destino que tuvo, y en que continuó durante su mansión; y en su virtud se le alza la detención doméstica, poniéndole en plena libertad; y por el justo motivo y modo de proceder, como propone el Promotor fiscal, se le condena en costas a justa tasación.

Pasó esta sentencia para su aprobación o reprobación a la Audiencia Territorial de Madrid, y después de haber oído por escrito al Fiscal de ella, con fecha de 30 de abril de 1814, declaró de conformidad la Sala del crimen, compuesta de cinco Ministros, que esta causa no debe perjudicar a su buena conducta, y opinión; que se abra la detención doméstica que sufre dicho Bermúdez y la condenación en costas que se le ha impuesto, dándole los testimonios que pidiere y señalare de dicha causa para el uso que le convenga.

Ya estaban entonces en Madrid las Cortes y la Regencia del reino, que tres meses antes habían venido de Cádiz. Acompañárala un enjambre de dos clases de gentes, que andaban en derredor de la colmena de los empleos. La primera venía 
ya en posesión de ellos, que alcanzara con el título de primer patriota de la nación, no embargante de que muchos de los que componían esta clase privilegiada, habían jurado a Josef, concurrido a su corte, algunos defendiendo a todo trance sus usurpados derechos, y casi todos pormancido en su servicio mientras durarun sus empleos, y de que luego que fueron extinguidos, corrieron a Andalucía, blasonando de leales, como si el sólo hecho de haber emigrado fuese un mérito, y baldonando un gobierno, cuyo amparo y protección acababan de mendigar; y en el que ciertamente hubieran proseguido si los franceses no hubiesen extinguido sus destinos. La segunda era de sujetos desennocidos, los más de baja estofa, sin letras unos, y sin costumbres otros, que jamás habían tenido cargo ni destino alguno, y que para conseguido adulaban a los de lat primera clase, dividida en bandos, y eran la tropa auxiliar de que se valían estos para sostener sus opiniones y para vituperar las de sus contrarios.

Y aunque los de uno y otro bando se odiaban cruelmente entre sí, se agabillaban cuando se trataba de restituir o conferir empleos a los que no habían estado en Cádiz y se habían quedado en Madrid, que era el mayor delito que entonces se conocía en aquella república, sin distinguir los buenos de los malos, y sin querer premiar a los que habian urabajado por la patria en medio de los enemigos. Imbuidos en esta máxima todos los dé ambos partidos, así próceres, como satélites, revueltos y amalgamados en aquel torbellino impetuoso, que vino de mediodía, embistieron y atropellaron con ferocidad a los infielices que habían quedado en sus hogares, haciendo rostro a los franceses y desempeñando con puréza sus destinos. No de otra manera, que cuando entraron por aquella banda en el reino los bárbaros sarracenos no dejando ningún cristiamo en su puesto; o como cuando en el es* tío se desprende de una nube parda un repentino aguacero, que cayendo sobre la preparada semilla, envuelta en el ardiente polvo, vivilica súbitamente mil ponzoñosos escuerzos, que saltando de acá para acullá, arremeten a otros inocentes insectos, que tranquilos buscan su alimento en el terreno que les señaló la Providencia. ajCún desapoderado y perjudicial (dería un político) es la ambición y el apetito de mandar! Todo lo revuelve y lo trueca, sin tener euenta con la infamia, ni lo que la modestia y templanza piden*.

Se apareció en Madrid el mayo siguiente, cuando no se esperaba, el rey D. Fernando, que volvía de su cautiverio, y con su presencia desaparecieron la regencia y las cortes. S.M. penetrado de las distintas causas que obran el corazón humano en tiempo de revolución, y compadecido de su miseria y fragilidad, se dignó mandar pocos días después, que se circulase por las Secretarías de Estado una real orden, concebida en estos términos: a'Teniendo el Rey en consideración, que las extraordinarias circunstancias en que se había hallado la monarquía durante su ausencia, habían dado motivo a los que tuvieron el honor de servirle en las Secretarías de Estado, y en otros destinos, de manifestar con sus obras y conductas, si 
eran dignos de continuar en su real servicio, si merecían ser separados de él, conociendo al mismo tiempo que no de todos los hombres pueden exigirse esfuerzos de heroísmo, y que entre éste y la falta de lealtad hay grados intermedios, que no deben confundirse; y a fin de evitarlo, tuvo a bien de nombrar S.M. varias juntas, compuestas cada una de tres magistrados, en las que después de examinar la condueta política, que hubiesen tenido en dicha época los empleados de sus respectvos ramos, y de tomar los informes convenientes para su justificación, los dividiesen en cuatro clases, poniendo en la primera los que no habian tomado empleo del usurpador, en la segunda los que le habían servido en los mismos empleos que antes tenían, en la tercera los que tuvieron ascensos, que no fuesen de escala, o distinciones, que diesen lugar a presumir, que habían servido al usurpador, no por debilidad, o estimulados por la miseria, sino por inclinación, y en la cuarta, los que no contentos con servirle, habían contribuido a extender su partido, seduciendo a otros, o persiguiendo a los buenos.

Ceán Bermúdez, en vista de tan justa como benigna determinación, presentó a los tres Jueces nombrados para la clasificación de los empleados del ramo de Gracia y Justicia, un testimonio de lo principal, que contenía la causa, que se le había formado, y una información original, actuada ante las Justicias de Sevilla, en la que el Rdo. Obispo auxiliar de aquella diócesis y su gobernador durante la dominación francesa; un Dignidad, que entonces presidía el cabildo de la Catedral; y un Prebendado, que fue secretario del gobierno eclesiástico, con quienes Ceán Bermúdez había tenido seguida y reservada correspondencia, depusieron, que babía evitado con celo, tino y prudencia, que se declarase la sede vacante del arzobispado, y la reunión de los monasterios de monjas de aquella ciudad, contra lo dispuesto por aquel comisario regio; que había contribuido con eficacia a que volviesen a su iglesia los cuatro canónigos, que el mariscal Soult, habra desterrado a Jaén; que habia entretenido por mucho tiempo la provisión de curatos de la diócesis; que había impedido otros grandes males a que estaba amenazada; y que había hecho muchos bienes en su favor y del cabildo, de quienes había sido un verdadero agente oculto, con inminente riesgo de su persona.

Los magistrados pidieron la causa original y en virtud de lo que de ella, de la citada información y de otros informes reservados resultó, expusieron al rey su parecer por et Ministerio de Gracia y Justicia. Pero no se dio curso en él a este expediente por haberle perdido, u ocultado, los que tenían interés y empeño en que el editor no volviese a la Secretaría; hasta que pasados cinco meses le subio al despacho otro Ministro nuevo, después de haber tomado informes secretos de dos sujetos eondecorados y de toda la conFianza de S.M. sobre chismes, que los tales interesados levantahan de nuevo. iAh!... iA cuántas alteraciones están expuestas la suerte y opinión del desgraciado! Las advertencias se suceden unas a otras; y de un mal se tropieza en otro, sin poderlo reparar. 
Satisfecho el Rey de la sama conducta y lealtad de Ceán Bermúderz, se dignó señalarle en $1 .^{\circ}$ de enero de 1815 las dos terceras partes de su sueldo, lo que le avisó el propio Ministro immediatamente y con reserva por un amigo y confidente suyo. Y no siendo esto, como no lo fuc, ninguna ficción, a moyana, iquién se atrevería a dudarlo, o a sospechar, que no tendría efecto? Quien hubiese reparado en lo que dice un filósofo historiador nuestro: «Los ruines y gentes de malas mañas, con chismes y decir mal de otros, acontece ser antepuestos a los buenos y modestos*. Se desataron entonces la envidia, el rencor, la calumnia y otros monstruos, que tienen su guarida en los palacios de los príncipes: ninguno quiso pasarle el oficio acostumbrado, avisándole esta gracia: se dispuso que un diligente y astuto alguacil indagase cuál había sido y era de presente su conducta en Madrid y cuál la opinión que se tenía de él en su barrio; y aunque en todas partes no encontró el esbiro más que desengaños, la saña de los malsines recurrió a nuevos y soñados delitos, que ni la astucia, ni la seducción, ni la supuesta autoridad pudieron probar.

Pero como la calumnia tiene a las veces más fuerza que la verdad, y la mentira es más artificiosa que ella, el Ministro que conocía a Bermúdez de trato íntimo más hacía de veinte años, y que le constaba su inocencia, por haber sido uno de los tres Magistrados que habían antes examinado su causa, e intormado a S.M. de su conducta política, compadecido de su suerte, y para que no pereciese su familia, a quien no podía ni debía mirar con ingratitud, ni aun con indiferencia, como decía entonces otro magistrado, autor y testigo de las estrechas relaciones que habia habido entre los dos, pudo componer, que las dos terceras partes señaladas por el rey, quedasen reducidas a 15.000 reales anuales, por víd de equidad y benignidad... Así consumó su sacrificio este Benemérito a la Iglesia de España, que tantas veces fue víctima de la justicia y de la amistad, y ahora lo es de la lealtad a su rey y a su patria, como lo justificó plenaria y solemnemente en tres tribunales y en juicio contradictorio. Mas tengan presente los malsines, que cuanto el humamo favor más se ensalza, tanto los hombres deben más humillarse, y temer los varios sucesos y desastres con la continua memoria de la humana incostancia: que los engaños e invenciones no duran; y que es justo juicio de Dios, que se atajen con el castigo del mismo que de ellos se valió. Así lo enseña todos los días la experiencia.

Esta certísima y prolija relación, que parece no venir a cuento para el objeto y argumento del Prólogo, además de presentar un ejemplo no común de honradez y patriotismo, y otro aún más extraordinario, por el modo con que ha sido compensado (lo que nadie debe ignorar para su aprovechamienta), refiere la causa de la última interrupción, que tuvieron las Noticins de los arquitectos y arquitectura de España, que impidió el haberse concluido y lal vez el haberse impreso; por lo que pareció justo y necesario no omitirla, y porque lo fue también del estado y situación en que al presente se halla el editor. 
La situación no puede ser más ventajosa para la obra, ni la tuvo mejor para perfeccionarse, desde que salió de las manos de su primitivo autor. Tranquilo en su cuarto el adicionador, rodeado de preciosos mss. de planes de edificios y canales, de papeles curiosos, de libros eseogidos, de dibujos originales, y de muchas antiguas y apreciables estampas, que le instruyen y divierten; dueño de todo el espacio, que hay desde que el sol asoma por el oriente, hasta que se precipita en occidente, sin que nadie le incomode con visitas impertinentes (privilegio que sólo gozan los caídos desde el punto en que los abandona la fortuna), no tiene otro trato ni familiaridad que con los muertos (cuales son los arquitectos antiguos), gente harto más honrada, pacífica y callada, que los vivos; no sabe ni indaga otras novedades que las que le comunican aquellos de dos o más siglos, con lo que adelanta sobremanera en su obra y logra no ser sospechoso a la Seguridad pública.

Es verdad, que diariamente intenta perturbarle su sosiego el hambre, enemigo despiadado en estos tiempos de los hombres virtuosos y retirados, pero procura entretenerla, pasando al gabinete de su hija, joven de trece años, quien le tañe una o dos sonatas de Mozart, Pleyel, o Haidem: en el forte-piano,
A cuyo son divino
El alma, que en olvido está sumida,
Torna a cobrar el tino
Y memoria perdida,
De su origen primero esclarecida****.

Con lo que, y con lo poco que produce la mal cobrada pensión, que le han dejado, vive sosegado y pacífico,
A solas, sin testigo,
Libre de amor, de celo,
De odio, de esperanzas, de recelo******.

En tan blanda y tranquila situación, temeroso de que se la arrebate la muerte, que ya no puede estar muy lejana, pues no hay bienandanza que dure, ni descanso que presto no se mude en contrario, se adelantó, antes de acabar la obra de los arquitectos, a escribir su Prólogo, seguro de que ninguno podrá hacerlo con tanta certeza e individualidad, como él mismo. También le movió a ello la consideración del menoscabo que se la podría seguir de que el que la leyere no estuviese instruido de lo que había trabajado en ella el autor, de lo que había añadido el editor, y de los motivos que hubo para retardarse su impresión, después de haber

\footnotetext{
**** Fr. Luis de León: canción a Francisco de Salinas.

***** El mismo: olra de la Vida Solitaria.
} 
sido anunciada tantos años hace y suspirada de los sabios y amantes de las bellas artes: circunstancias, que merecen su lugar en los anales de la literatura española, en la historia de las mismas nobles artes, y aún hasta en la de la revolución del reino.

Si esta previsión, si el mérito del Sor. Llaguno, y el desvelo de Ceán Bermúdez no lograsen el aprecio de los venideros, en caso de que los venideros lleguen al estado de poder apreciar obras de esta clase, porque los ingenios de los hombres son como algunos animales y semillas, que con el tiempo degeneran y se estragan, sino se pone sumo cuidado en fomentarlos, no hay que esperar ninguna recompensa de estimación y de honor, visto el resultado de la causa, arriba extractada; y visto el ningún estímulo de lo que deben proteger semejantes empresas.

Ya es liempo de poner término a este Prólogo, o discurso, en el que si ha corrido la pluma con calor, tue a impulso del agravio y de la calumnia; porque si no está bien a los miserables hacer alarde de sus cuitas, las cuitas cuando son extremas hacen que los miserables hablen con energia.

[Juan Agustín Ceán Bermúdez] 